\title{
Hydrodynamic shear stress promotes epithelial-mesenchymal transition by downregulating ERK and GSK3 $\beta$ activities
}

Hye Yeon Choi ${ }^{1}$, Gwang-Mo Yang ${ }^{1}$, Ahmed Abdal Dayem', Subbroto Kumar Saha ${ }^{1}$, Kyeongseok Kim', Youngbum Yoo ${ }^{3}$, Kwonho Hong ${ }^{1}$, Jin-Hoi Kim', Cassian Yee ${ }^{4}$, Kyung-Mi Lee ${ }^{2^{*}}$ and Ssang-Goo Cho ${ }^{1 *}$ (D)

\begin{abstract}
Background: Epithelial-mesenchymal transition (EMT) occurs in the tumor microenvironment and presents an important mechanism of tumor cell intravasation, stemness acquisition, and metastasis. During metastasis, tumor cells enter the circulation to gain access to distant tissues, but how this fluid microenvironment influences cancer cell biology is poorly understood.

Methods and results: Here, we present both in vivo and in vitro evidence that EMT-like transition also occurs in circulating tumor cells (CTCS) as a result of hydrodynamic shear stress (+SS), which promotes conversion of $\mathrm{CD} 24^{\text {middle }} / \mathrm{CD} 44^{\text {high }} / \mathrm{CD} 133^{\text {middle }} / \mathrm{CXCR} 4^{\text {low }} / \mathrm{ALDH} 1^{\text {low }}$ primary patient epithelial tumor cells into specific high sphere-forming CD24 low $/ C D 44^{\text {low }} / \mathrm{CD} 133^{\text {high }} / \mathrm{CXCR} 4^{\text {high }} / \mathrm{ALDH} 1^{\text {high }}$ cancer stem-like cells (CSLCs) or tumor-initiating cells (TICS) with elevated tumor progression and metastasis capacity in vitro and in vivo. We demonstrate that conversion of CSLCS/TICs from epithelial tumor cells via +SS is dependent on reactive oxygen species (ROS)/nitric oxide (NO) generation, and suppression of extracellular signal-related kinase (ERK)/glycogen synthase kinase (GSK) $3 \beta$, a mechanism similar to that operating in embryonic stem cells to prevent their differentiation while promoting self-renewal.

Conclusion: Fluid shear stress experienced during systemic circulation of human breast tumor cells can lead to specific acquisition of mesenchymal stem cell (MSC)-like potential that promotes EMT, mesenchymal-epithelial transition, and metastasis to distant organs. Our data revealed that biomechanical forces appeared to be important microenvironmental factors that not only drive hematopoietic development but also lead to acquisition of CSLCS/ TIC potential in cancer metastasis. Our data highlight that +SS is a critical factor that promotes the conversion of CTCs into distinct TICs in blood circulation by endowing plasticity to these cells and by maintaining their selfrenewal signaling pathways.
\end{abstract}

Keywords: Tumor-initiating cells, Hydrodynamic shear stress, ROS/NO, EMT/MET, ERK-GSK3 $\beta$

\section{Background}

Cancer metastasis involves a series of sequential steps including epithelial mesenchymal transition (EMT) of primary tumor cells into tumor-initiating cells (TICs) and

\footnotetext{
* Correspondence: kyunglee@korea.ac.kr; ssangoo@konkuk.ac.kr

${ }^{2}$ Department of Biochemistry and Molecular Biology, Korea University College of Medicine, 26-1 Anam-dong, Sungbuk-gu, Seoul 02841, Republic of Korea

${ }^{1}$ Department of Stem Cell \& Regenerative Biotechnology and Incurable Disease Animal Model and Stem Cell Institute (IDASI), Konkuk University, 120 Neungdong-ro, Gwangjin-gu, Seoul 05029, Republic of Korea

Full list of author information is available at the end of the article
}

their intravasation into the bloodstream as circulatingtumor cells (CTCs) [1]. Extravasation of CTCs at distant sites, where mesenchymal epithelial transition (MET) culminates, allows their proliferation as epithelial metastatic deposits [2]. CTCs have been detected in the majority of patients with breast cancer, where they represent cancer stem-like cells (CSLCs) or TICs captured as they transit through the bloodstream $[3,4]$.

Although the concept "seed and soil" or "TICs and hypoxic stromal niche" has been the prevailing determinant of EMT transition and metastasis of breast

(c) The Author(s). 2019 Open Access This article is distributed under the terms of the Creative Commons Attribution 4.0 International License (http://creativecommons.org/licenses/by/4.0/), which permits unrestricted use, distribution, and 
cancer [5], proliferating tumor cells near the periphery of solid tumor mass are prone to translocation into nearby blood vessels due to the nature of loose mosaic vessels that are formed within solid tumors, facilitated by chemotherapy-induced destruction of extracellular matrix (ECM) [6-8] and a remodeled tumor vasculature $[9,10]$. Once translocated into blood vessels, tumor cells present in blood vessels are continually exposed to severe shear stress (SS) under normoxic conditions, and subjected to cell cycle arrest due to hypoxic-to-normoxic transition and apoptosis from the absence of cell-ECM interaction and tumor growth factors. Therefore, only those CTCs acquiring EMT potential during systemic circulation can survive and metastasize to distant sites.

Typical SS is $1-6$ dyne $/ \mathrm{cm}^{2}$ for venous circulation and $15-20$ dyne $/ \mathrm{cm}^{2}$ for arterial circulation [11, 12]. It is gradually appreciated that the mechanical properties of both the tumor microenvironment and cancer cells themselves play a significant role in tumor progression and metastasis [13, 14]. SS exerts prominent force on normal cells and its effects on blood cells, endothelial cells, smooth muscle cells, and epithelial cells, have been broadly studied [15-17]. However, much less is known about the SS effect on intravascular tumor cells of epithelial origin.

Recent studies have demonstrated that SS exerted on circulating hematopoietic stem cells (HSCs) can trigger the onset of definitive hematopoiesis and embryogenesis [18]. Since cancer metastasis begins by the intravasation of tumor cells into the circulation [19-22], we hypothesized that hydrodynamic shear stress (+SS) given to tumor cells could also trigger stress-dependent transcriptional changes that allow transition of CTCs into CSLCs/TICs. Here, we provide both in vivo and in vitro evidence that the conversion from epithelial tumor cells into CSLCs/TICs can occur within blood vessels, due to +SS experienced during systemic circulation without additional requirement for growth factors or a hypoxic stromal niche.

\section{Methods}

\section{Cell culture and chemicals}

Breast tumor tissue specimens were collected from patients who underwent mammotomy biopsy of breast tumors at the Breast Cancer Center of Konkuk University Hospital, with Institutional Review Board (IRB, KUH 1020003) approval. Breast tumor tissues from patients with stage III breast cancer treated with neoadjuvant chemotherapy (four cycles of preoperative doxorubicin and cyclophosphamide) were washed with PBS (GE Healthcare Hyclone) and incubated with type IV collagenase (Sigma-Aldrich) for $20 \mathrm{~min}$ at room temperature. A single-cell suspension was obtained by filtering the supernatant through a $100-\mu \mathrm{m}$ cell strainer (BD Bioscience) and was cultured in DMEM (GE Healthcare Hyclone) supplemented with $10 \%$ fetal bovine serum (FBS; GE Healthcare Hyclone) and 1\% P/S (100 U/ml penicillin/streptomycin; GE Healthcare Hyclone) at $37{ }^{\circ} \mathrm{C}$ with $5 \% \mathrm{CO}_{2}$. Unless stated otherwise, cells were cultured on the adherent tissue culture plates (Nunc). The study also included breast tumor tissues obtained from 45 patients for CSLC analysis (Additional file 1: Table S1). MDA-MB231 cells (American Type Culture Collection (ATCC)) were cultured in RPMI-1640 medium (Gibco-BRL), supplemented with $10 \% \mathrm{FBS}$ and $1 \% \mathrm{P} / \mathrm{S}$ at $37{ }^{\circ} \mathrm{C}$ with $5 \% \mathrm{CO}_{2}$. The breast cancer cells (MCF7) were cultured in DMEM supplemented with $10 \% \mathrm{FBS}$ and $1 \% \mathrm{P} / \mathrm{S}$ at $37{ }^{\circ} \mathrm{C}$ with $5 \% \mathrm{CO}_{2}$. The hepatic cancer (SNU447 and HepG2), colon cancer (HCT116 and HT29), and pancreatic cancer (Panc2 and Capan1) cell lines were cultured in DMEM supplemented with $10 \% \mathrm{FBS}$ and $1 \% \mathrm{P} / \mathrm{S}$ at $37{ }^{\circ} \mathrm{C}$ with $5 \% \mathrm{CO}_{2}$. Cell viability was assessed by performing trypan blue exclusion assay and cells were counted with a hemocytometer. Doxorubicin (Sigma-Aldrich) and paclitaxel (Calbiochem) were dissolved in dimethyl sulfoxide (DMSO) (Sigma-Aldrich). BIO (GSK3 $\beta$ inhibitor), PD98059 (mitogen-activated protein kinase (MAPK) kinase (MEK) inhibitor), SB203580 (p38 MAPK inhibitor), and SP600125 (c-Jun $\mathrm{N}$-terminal kinase (JNK) inhibitor) were purchased from EMD Millipore.

\section{Application of hydrodynamic shear stress in vitro}

Hydrodynamic shear stress (+SS), which mimicked SS exerted during blood circulation in vivo, was applied on cell cultures using an orbital shaker (DAIHAN Scientific, Model SHO-1D) [23-27]. Tumor cells in DMEM containing $10 \% \mathrm{FBS}$ and $1 \% \mathrm{P} / \mathrm{S}$ were placed in non-coated Petri dishes (Nunc) and cultured on top of an orbital shaker at $60 \mathrm{rpm}$ for 10 days. Medium was changed every 2 days. After 3, 5, 7, and 10 days, the suspended and adherent cells were harvested separately. SS applied on cell culture plates was estimated using the formula:

$$
\tau_{\max }=\mathrm{a} \sqrt{\eta \rho(2 \pi \mathrm{f}) 3}
$$

where a is the orbital radius of rotation of the shaker, $\rho$ is the density of the culture medium $(0.9973 \mathrm{~g} / \mathrm{ml}), \eta$ is the viscosity of the medium $(0.0101 \mathrm{P}$ measured with a viscometer), and $\mathrm{f}$ is the frequency of rotation (rotation/ sec) [23]. Alternatively, confluent tumor cells, cultured in DMEM supplemented with $10 \% \mathrm{FBS}$ and $1 \% \mathrm{P} / \mathrm{S}$ in non-coated Petri-dishes, were exposed to flow in an in vitro fluid SS device, the cone-and-plate viscometer. Unidirectional steady flows at SS of 20 dyne $/ \mathrm{cm}^{2}$ (270 rpm) were applied to the cells to investigate the effect of laminar shear stress (LSS) [23] and bi-directional disturbed flows at $67 \mathrm{rpm}$ corresponding to SS of 5 
dyne $/ \mathrm{cm}^{2}$ were applied to the cells to examine the effect of oscillatory shear stress (OSS) [23].

\section{Sphere formation assay}

To evaluate the self-renewal and differentiation capacity of tumor cells at the single-cell level in vitro, 10,000 tumor cells were cultured in sphere-forming medium ((SFM): DMEM/F12 (Gibco-BRL) supplemented with B27-supplement (dilution, 1:50; Invitrogen), $20 \mathrm{ng} / \mathrm{ml}$ epidermal growth factor (EGF; Sigma-Aldrich), $10 \mu \mathrm{g} / \mathrm{ml}$ insulin (Sigma-Aldrich), and 0.4\% BSA (bovine serum albumin; Sigma-Aldrich)] for 3 days in non-coated Petri dishes, as described previously [28]. The number of spheres was assessed by trypan blue exclusion staining and counted with a hemocytometer.

\section{Tumor implantation and metastasis studies}

All animal experiments were performed in accordance with the Guide for the Care and Use of Laboratory Animals under approval by $\mathrm{t}$ he Institutional Animal Care and Use Committee (IACUC) of Konkuk University (KU11039 and KU12076).

For preparation of the bio-fluorescent green fluorescent protein (GFP) ${ }^{+}$MDA-MB231, CT-PC (breast cancer cells derived from chemotherapy-treated patients), or CT + SS (CT-PCs generated upon +SS) cells, HEK293T cells were first transfected with the GFP-expressing lentiviral vector, pCD521A (pCDH-EF1-T2A-copGFP), and viral packaging vectors using the calcium phosphate transfection protocol. After 5 days, the virus was harvested and concentrated using an ultracentrifuge (Optima L-90 K, Beckman Coulter Inc.). Then, MDA-MB231, CT-PC, or CT + SS cells were infected with lentivirus and incubated overnight at $37{ }^{\circ} \mathrm{C}$ with $5 \% \mathrm{CO}_{2}$. To measure virus titer, we used the equation as previously described [29]:

$\mathrm{IU} / \mathrm{ml}=[\{(\#$ Cells at starting time $) \times($ Dilution factor $)$

$\times($ Percentage of infection $)\} /($ Volume virus solution added expressed in $\mathrm{ml})]$

Viral injection efficiency was calculated to be $<95 \%$, and $\sim 7.8 \times 10^{8} \mathrm{IU} / \mathrm{ml}$ viral particles were used to prepare bio-fluorescent $\mathrm{GFP}^{+}$cells. The bio-fluorescent $\mathrm{GFP}^{+}$cells $\left(2 \times 10^{5}\right.$ cells) were injected into the mammary fat pads or left ventricle of female immune-deficient (NOD-SCID) or nude mice. Control group mice were injected with $100 \mu \mathrm{l}$ PBS only. At 1 or 2 days after injection, GFP+ fluorescence was measured using the Xenogen IVIS SPECTRUM (Perkin Elmer). At 2 and 28 days after injection, whole blood was collected using heparin-coated capillary tubes for further analysis. Lysis of erythrocytes (red blood cells (RBC)) was performed as previously reported [30]. Cells from the tibia were isolated using $8 \mathrm{ml}$ of ice-cold PBS and were RBC-lysed with ammonium-chloride-potassium (ACK) lysing buffer (1.5 M NH $\mathrm{NH}_{4} \mathrm{Cl}$ (Sigma-Aldrich),
$100 \mathrm{mM} \mathrm{KHCO}$ (Sigma-Aldrich), $10 \mathrm{mM}$ EDTA (Gibco-BRL), pH 7.2). After RBC lysis, the $\mathrm{GFP}^{+}$cells in the blood or tibia were sorted for GFP+ populations using FACSVantage $^{\mathrm{Tw}}$ flow cytometer (Becton Dickinson). Cells from the mammary fat pad were excised into small pieces of mammary gland and digested using $3 \mathrm{ml}$ DMEM/F12 with $0.5 \%$ collagenase (Sigma-Aldrich) and $0.5 \%$ hyaluronidase (Sigma-Aldrich). After $3 \mathrm{~h}$, the tissues were washed three times in PBS containing 1\% FBS. Cells were collected by centrifugation and plated on $0.03 \%$ collagen-coated cell culture plates in DMEM supplemented with $10 \%$ FBS for further RNA and protein analysis. Tumor volumes were calculated as:

$$
\text { Volume }\left(\mathrm{mm}^{3}\right)=\text { lLength } \times \text { width }^{2} \times 0.5 \text {. }
$$

For serial tumor re-transplantation assay, 100-10,000 $\left(10^{2}-10^{4}\right)$ tumor cells were implanted subcutaneously onto NOD/SCID mice. After tumors were formed, tumors from the first xenografts were excised from the primary recipients, dissociated into a single-cell suspension, grown in adherent culture conditions on gelatin-coated tissue culture plates for approximately 1 week, and then re-injected into secondary mouse recipients.

For orthotopic transplantation analysis of CT-PC or $\mathrm{CT}+\mathrm{SS}$, cells (each $1 \times 10^{4}$ cells) were grafted into the mammary fat pad of female NOD/SCID mice. At 4 or 8 weeks after injection, $\mathrm{GFP}^{+}$fluorescent images were obtained using Xenogen (Caliper life science) IVIS SPECTRUM and the $\mathrm{GFP}^{+}$cells in the blood were sorted and counted for $\mathrm{GFP}^{+}$populations using the FACSVantage $\mathrm{e}^{\text {tw }}$ flow cytometer.

To determine the serum ionized calcium levels as a measure of metastasis, ionized calcium was measured using an ABL800 analyzer (Radiometer). Serum albumin was detected using an Olympus AU4500 (Olympus) automatic chemical analyzer. Serum calcium was calculated using the Payne formula:

Corrected calcium $(\mathrm{mg} / \mathrm{dl})=$ Total calcium $(\mathrm{mg} / \mathrm{dl})+0.8 \times[4-\operatorname{Albumin}(\mathrm{g} / \mathrm{dl})]$.

\section{Immuno-histochemical analysis}

For examination, slides were stained with hematoxylin and eosin (H\&E; Santa Cruz Biotechnology) according to standard protocols. For immunostaining, sections were incubated with anti-N-CADHERIN (1:500; Santa Cruz Biotechnology), anti-E-CADHERIN (1:500; Santa Cruz Biotechnology), or anti-TWIST (1:500; Santa Cruz Biotechnology) antibody in $0.5 \%$ blocking buffer (normal goat serum; Vector Laboratory). The sections were washed and incubated with anti-mouse or anti-rabbit secondary antibody (EMD Millipore) diluted 1:1,000 in blocking buffer for $1 \mathrm{~h}$ at room temperature. Vectastain Elite $\mathrm{ABC}$ and diaminobenzidine substrate kits were 
used for immunoperoxidase staining according to the manufacturer's instructions (Vector Laboratories).

\section{Migration and invasion assays}

Cells, grown to $90 \%$ confluence, were pretreated with $25 \mu \mathrm{g} / \mathrm{ml}$ mitomycin C (Sigma-Aldrich) for $1 \mathrm{~h}$. A wound was created using a 2-mm pipette tip. Cells were rinsed briefly in PBS, complete medium was added, and migration into the wound was monitored at the indicated time points by imaging at $\times 40$ magnification. Cell invasion was assessed using the Cell Invasion Assay Kit (Chemicon). Briefly, polycarbonate filters were coated with ECMatrix and placed in a transwell chamber. Medium, with or without $10 \%$ FBS, was added to the lower compartment of the chamber, then $3 \times 10^{5}$ cells, suspended in DMEM without FBS, were added to the upper compartment. After $24 \mathrm{~h}$ incubation at $37^{\circ} \mathrm{C}$, the filters were fixed with methanol and the number of cells that had invaded through the basement membrane was counted.

\section{RNA sequencing analysis (RNA-seq.) and quantitative real- time PCR}

For RNA seq. analysis, RNA libraries were prepared from $100 \mathrm{ng}$ of total RNA from each sample according to the manufacturer's instruction (www.lascience.co.kr), and sequenced on an Illumina HiSeq 2000 using TruSeq SBS sequencing software (version 3). Genes presenting at least twofold difference between groups with a $p$ value $<0.05$ were considered differentially expressed.

Quantitative real-time PCR was performed using total cellular RNAs purified from cultured cells using Trizol reagent (Invitrogen) according to the manufacturer's protocol. The extracted RNA samples were subsequently treated with MMLV reverse transcriptase (Promega). PCR products were analyzed on $1 \%$ or $1.2 \%$ agarose gels (Invitrogen) and analyzed using SsoFast EvaGreen Supermix (Bio-Rad). Quantification of gene expression was performed only in the linear range for each primer pair. The delta-delta cycle threshold (DDCT) method [31] was used to quantify changes in the expression of each specific gene normalized to the expression of the housekeeping gene gapdh. The sequences of primers used for amplification are provided in Additional file 2: Table S2.

\section{Western blot analysis}

To prepare whole-cell extracts, cells were scraped from the dishes and suspended in protein extraction buffer (100 mM Tris-Cl (Sigma-Aldrich) pH 7.8, $10 \mathrm{mM} \mathrm{NaCl}$ (Sigma-Aldrich), 10\% glycerol (Sigma-Aldrich), $1 \mathrm{mM}$ sodium orthovanadate (Sigma-Aldrich), $50 \mathrm{mM}$ sodium fluoride (Sigma-Aldrich), and $1 \mathrm{mM}$ phenymethylsulfonyl fluoride (Sigma-Aldrich). Equal amounts of protein were separated by electrophoresis on 10\% SDS-polyacrylamide gels, followed by electrophoretic transfer to nitrocellulose membranes (EMD Millipore). Membranes were blocked in 5\% nonfat dry milk (Amresco LLC) and 0.1\% Tween-20 (Amresco LLC) in Tris-buffered saline and probed with the following primary antibodies; the anti-ERK, anti-JNK, anti-p38, anti-phospho-JNK, anti-MEK, anti-FLAG, anti-p53, anti-p21, anti-GSK3 $\beta$, and anti-ACTIN (Santa Cruz Biotechnology), anti-phospho-ERK, anti-phosphop38, anti-phospho-GSK3 3 (Ser9), and anti-phospho-MEK (Cell Signaling). Antibody-antigen complexes were incubated with anti-rabbit or anti-mouse-IgG-peroxidase conjugates (Santa Cruz Biotechnology), followed by detection using an enhanced chemiluminescence (ECL) kit (GE Healthcare Life Sciences).

\section{Measurement of intracellular reactive oxygen species (ROS) and nitric oxide (NO)}

For analysis of intracellular ROS levels, cells treated with $1 \mathrm{mM} \mathrm{N}$-acetylcysteine (NAC; Sigma-Aldrich) for $1 \mathrm{~h}$,

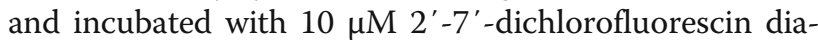
cetate $\left(\mathrm{H}_{2}\right.$-DCFH-DA) (Invitrogen) for $30 \mathrm{~min}$ at $37{ }^{\circ} \mathrm{C}$ in the dark. Then, the cells were washed twice with PBS, analyzed by FACScan flow cytometer and Cell Quest 3.2 software (Becton, Dickinson and Company).

Intracellular NO was detected using an OxiSelect ${ }^{\mathrm{m}}$ Intracellular Oxide Assay kit (Cell Biolabs Inc) according to the manufacturer's instruction. In brief, $2 \times 10^{5}$ cells were seeded in 6-well culture plates and grown for $24 \mathrm{~h}$. Prior to the experiment, the cells were incubated with $1 \mathrm{mM}$ L-NAME (NOS inhibitor, $\mathrm{N}(\mathrm{G})$-nitro-l-argininemethyl ester, Sigma-Aldrich) for $1 \mathrm{~h}$. The cells were rinsed twice with PBS and then incubated for $2 \mathrm{~h}$ at $37^{\circ} \mathrm{C}$ under $5 \% \mathrm{CO}_{2}$ in the presence of the NO probe. After $2 \mathrm{~h}$, the cells were lysed using lysis buffer and then the NO fluorescence was quantified using a SpectraFluor Plus device (Tecan Group Ltd.) set to excite at $485 \mathrm{~nm}$ and emit at $530 \mathrm{~nm}$.

\section{Plasmid transfection}

The pcDNA3-FLAG-tagged vectors containing either WT MEK or active MEK were introduced separately into CT + SS using Lipofectamine (Invitrogen). Stably expressing clones were selected using $1 \mu \mathrm{g} / \mathrm{ml} \mathrm{G} 418$ (Calbiochem) for 20 days. The selected cells were assessed for Flag expression by western blot analysis.

\section{Statistical analysis}

Data are shown as the mean \pm standard error (SEM). Statistical analyses were performed using the two-tailed Student $t$ test for two groups, in Excel (Microsoft, Redmond, WA, USA) or InStat 3 (GraphPad software, La Jolla, CA, USA). For the multiple comparison test, analysis of variance (ANOVA) was performed with Tukey-Kramer adjustment. A $p$ value $<0.05$ was considered statistically significant. 


\section{Results}

Hydrodynamic shear stress experienced during systemic circulation of tumor cells leads to acquisition of stemness and EMT potential

To initiate the metastatic spread of cancer, tumor cells are exposed to mechanical forces exerted by fluid SS, hydrostatic pressure, and tension $[13,16]$. We hypothesized that SS applied to tumor cells during systemic blood circulation may trigger the transition of epithelial tumor cells into TICs, similar to that observed in hematopoietic stem cells (HSCs). To test this hypothesis, we injected $\mathrm{GFP}^{+}$MDA-MB231 breast tumor cells directly into the left ventricles of the mice (Fig. 1a). Markedly elevated GFP signals were observed on day 28 after the injection, suggesting that CTCs remaining in blood circulation had undergone proliferation. The average number of bio-fluorescent $\mathrm{GFP}^{+}$cells harvested from $1 \mathrm{ml}$ blood was $2.3 \times 10^{4}$ cells on day 2 after the injection, which was approximately $12 \%$ of the total number of tumor cells (Fig. 1a). The number of $\mathrm{GFP}^{+}$tumor cells in the blood increased to $\sim 2.6 \times 10^{5}$ cells by day 28 after the intra-cardiac injection. Importantly, circulating $\mathrm{GFP}^{+}$ tumor cells had significantly enhanced expression of Nanog, Sox2, and Oct4 (Oct4B and Oct4B1) compared with those directly injected into the mammary fat pads (Fig. 1b). On day 28, expression levels of Nanog, Sox2, and Oct4 in circulating $\mathrm{GFP}^{+}$cells and cells injected into mammary fat pads (orthotopical (OT) injection) were similar, suggesting that static tumor cells acquire stemness property in the tumor microenvironment. More importantly, CTCs metastasizing to the tibia and the mammary fat pads at day 28 following intra-cardiac injection demonstrated even higher levels of all three stemness factors than those in circulation. These data suggest that CTCs had undergone epithelial-mesenchymal-like transition during circulation and that further stemness properties were acquired at the tumor site where the MET process culminated. Consistently, results of sphere formation assay showed that circulating $\mathrm{GFP}^{+}$tumor cells formed more spheres than static $\mathrm{GFP}^{+}$tumor cells harvested from the mammary fat pads (Fig. 1c, left panel). Moreover, $\mathrm{GFP}^{+}$ tumor cells harvested from the metastasized tibias and mammary fat pads of mice on day 28 had significantly greater sphere formation ability (Fig. 1c, right panel) and expression of EMT genes, including $N$-cadherin, Twist, Snail1, and Vimentin, than those in circulation or injected into the mammary fat pads (Fig. 1d left panel). Furthermore, expression of epithelial markers, such as E-Cadherin, Claudin-7, and Cytokeratin-8, were significantly decreased in circulation or injected into the mammary fat pads (Fig. 1d right panel). Expression of SS-induced genes, such as Early growth response 1 (Egr1) [32], Activator protein 1 (Ap1) [33], Epithelial cell adhesion molecule (Epcam) [34], and Kruppel-like factor 8 (Klf8) [35], were the highest in the circulating $\mathrm{GFP}^{+}$tumor cells (Fig. 1e and $\mathrm{f}$ ). Although Klf2 was reported to be one of the KLF family proteins the expression of which in vascular endothelium was induced by SS [36], its expression was not increased in circulating $\mathrm{GFP}^{+}$tumor cells in the present study.

In contrast, marginal increase of SS-induced genes in static mammary tumors or those metastasized to the tibias and mammary fat pads were noted, indicating that CTCs are under the influence of severe SS. These data suggest that fluid SS experienced during systemic circulation of human breast tumor cells can lead to specific acquisition of mesenchymal stem cell (MSC)-like potential that promotes EMT, MET, and metastasis to distant organs.

Shear stress induced by repeated shaking and suspension in vitro drives the conversion of MDA-MB231 tumor cells into high sphere-forming TICs

We investigated whether SS given during blood circulation can be mimicked in vitro to induce the conversion of MDA-MB231 cells into TICs (Fig. 2a). Shear stress during blood circulation can be characterized as laminar, oscillatory, or hydrodynamic (Fig. 2a). At first, by using an in vitro fluid SS device, the cone-and-plate viscometer, we mimicked the SS exerted during a unidirectional steady flow (referred to as laminar shear stress (LSS)), which may be present in large straight segments of the arterial vasculature and is characterized by parallel layers of unidirectional flow with minimal disturbance between these layers [37]. Exposure of MDA-MB231 cells to high LSS (20 dyne $/ \mathrm{cm}^{2}$ ) (Fig. 2b) led to a slight increase in the number of suspension cells (Fig. 2b-i) and expression of SS-induced genes (Egr1, Ap1 and Epcam, Fig. 2b-ii). However, stemness factors (Nanog, Oct4B, and Sox2, Fig. 2b-iii), EMT markers (N-Cadherin, Twist, and Snail1, Fig. 2b-iv), and epithelial marker, E-Cadherin, Claudin-7, and Cytokeratin-8, Fig. 2b-v) showed no significant changes. Moreover, because bi-directional disturbed flow may correspond to blood flow in regions where arterial bifurcations and branch points are formed, which induce oscillating shear stress (OSS) [38], we also applied bi-directional disturbed flow to investigate the effect of OSS on CTCs. MDA-MB231 cells cultured under 5 dyne $/ \mathrm{cm}^{2}$ OSS for $24 \mathrm{~h}$ showed a significant increase in the number of suspension cells (Fig. 2c-i) and expression of SS-induced (Fig. 2c-ii), stemness factor (Fig. 2c-iii), and EMT marker (Fig. 2c-iv) genes, compared with control cells not cultured under LSS. Moreover, expression of epithelial markers was significantly decreased upon OSS, compared with that of control cells (Fig. 2c-v).

In addition, as the SS given on the cells during blood circulation is reported to be within 2-14 dyne $/ \mathrm{cm}^{2}$, 
a
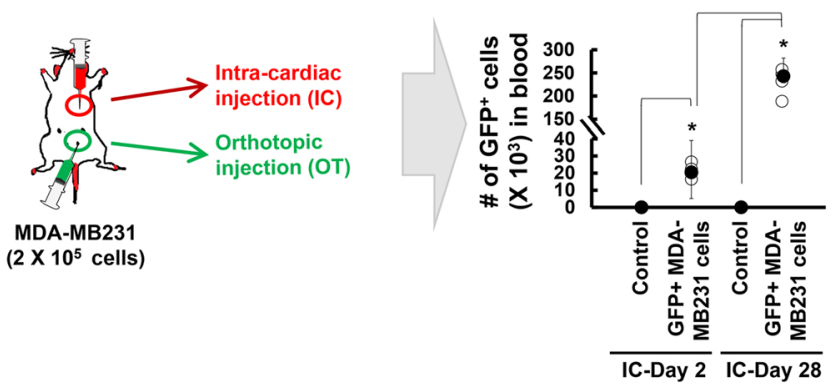

b
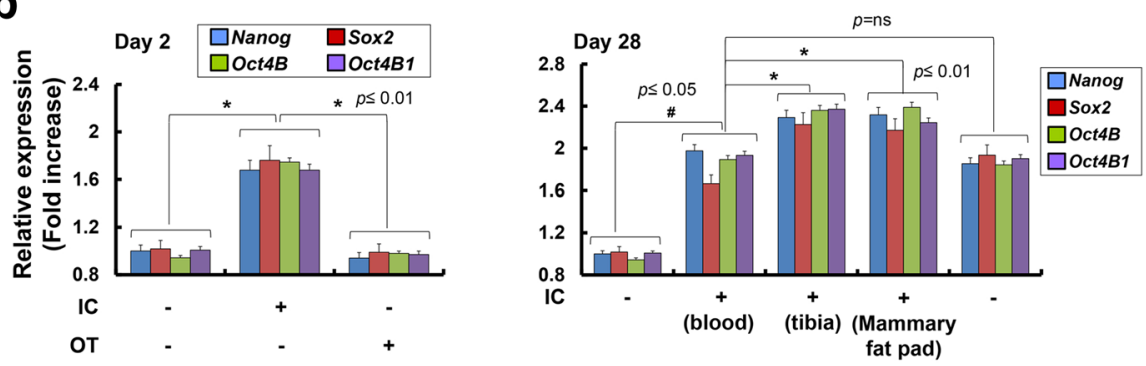

C
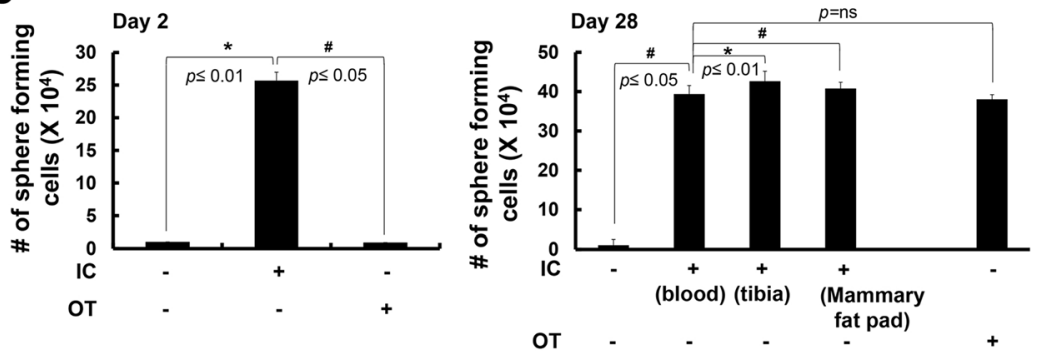

d Day 28 - EMT markers
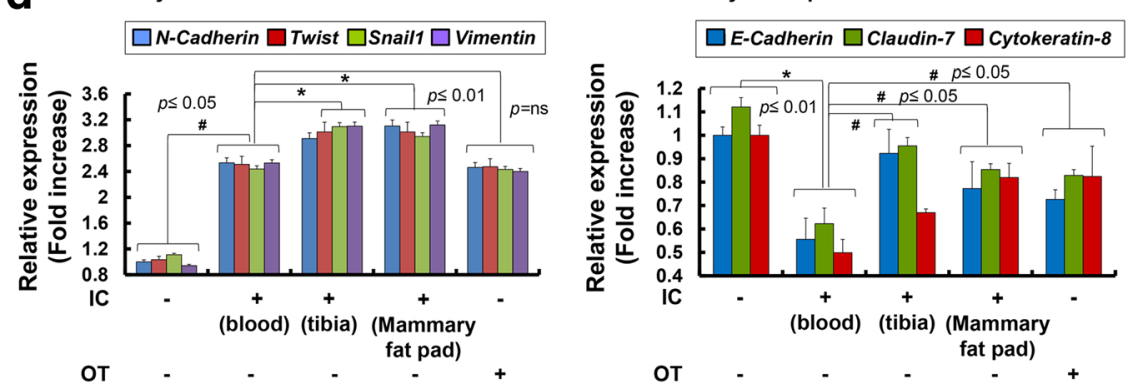

e

Day 2

$\square$ Epcam $\square K$ If8 $\square K / f 2$

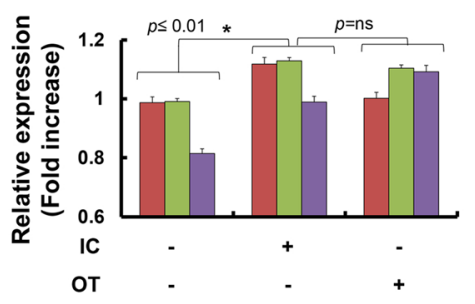

f

Day 28

$\square$ Egr1 $\square$ Ap1 $\square$ Epcam $\square$ KIf8 $\square$ Klf2

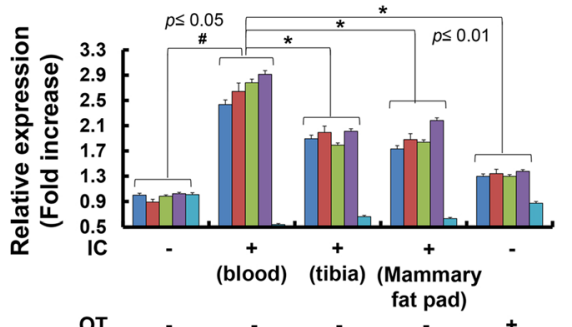

Fig. 1 (See legend on next page.) 
(See figure on previous page.)

Fig. 1 Analysis of tumor formation, transcriptional changes, and sphere-forming ability of MDA-MB231 cells harvested from the blood after intra-cardiac injection or from mammary fat pads after orthotopic injection. a Green fluorescent protein (GFP) ${ }^{+}$MDA-MB231 cells (density, $2 \times 10^{5}$ cells) were injected into the left ventricle of the heart or mammary fat pads of mice $(n=5)$. Right panel, the total bio-fluorescent GFP ${ }^{+}$cells in the whole blood from the intra-cardiac (IC)-injected mice or PBS-injected control mice were isolated by fluorescence-activated cell sorting (FACS) and the number of $\mathrm{GFP}^{+}$cells is presented. An average is shown as black circles; ${ }^{*} p<0.05$. $\mathbf{b}$ Expression of stemness marker genes (Nanog, Sox2, Oct4B, and Oct4B1) was analyzed by quantitative real-time RT-PCR at 2 or 28 days following IC or orthotopic (OT) administration of MDA-MB231 cells $(n=5)$. In mice where MDA-MB231 cells were injected systemically (IC), secondary tumors formed in the tibia and mammary fat pads, and their expression of stemness marker genes was significantly increased (Tibia, Mammary fat pads). c Sphere-forming capacity of GFP+ MDA-MB231 cells harvested at 2 or 28 days from mice directly injected into left ventricle of the heart or orthotopically implanted into mammary fat pads $(n=5)$. d Expression of the epithelial-mesenchymal transition (EMT) marker (N-Cadherin, Twist, Snaill, and Vimentin; left panel) and epithelial marker (E-Cadherin, Claudin-7, and Cytokeratin-8) genes on GFP+ MDA-MB231 cells harvested at 28 days from blood, tibia, and mammary fat pads analyzed by quantitative real-time RT-PCR $(n=5)$. Expression of the shear stress (SS)-induced genes (Egr1, Ap 1, Epcam, Klf8, and Klf2) on GFP+ MDA-MB231 cells harvested at 2 days (e) and 28 days ( $\mathbf{f}$ ) from blood, tibia, and mammary fat pads analyzed by quantitative real-time RT-PCR analysis $(n=5)$. Expression of each gene in quantitative real-time RT-PCR analysis was normalized to Gapdh. The data presented here are presented as mean \pm SEM and are representative of three independent experiments. Statistically significant differences are tested at $p<0.05$ significance

which corresponds to $30-210 \mathrm{rpm}$ of orbital shaking in vitro [39, 40], hydrodynamic shear stress $(+$ SS) exerted during blood circulation was mimicked using an orbital shaker. Several breast cancer MCF7 and MDA-MB231 cells, were cultured in non-coated Petri dishes under orbital shaking at 30-240 rpm, which corresponds to 2.25-18 dyne $/ \mathrm{cm}^{2}$. Among various SS tested, MDA-MB231 and MCF7 cells cultured at $60 \mathrm{rpm}$, corresponding to SS of 4.5 dyne $/ \mathrm{cm}^{2}$, showed a significant increase in the number of suspension cells (Fig. 2d), reaching a plateau by 7 days following orbital shaking in culture (Fig. 2e). Furthermore, we observed that several different cancer cells, including breast cancer MCF7 and MDA-MB231 cells, hepatic cancer SNU447 and HepG2 cells, colon cancer HCT116 and HT29 cells, and pancreatic cancer Panc2 and Capan1 cells, showed an apparent increase in the number of suspension cells and, in particular, breast or hepatic cancer cells cultured at $60 \mathrm{rpm}$, corresponding to SS of 4.5 dyne $/ \mathrm{cm}^{2}$, showed a significant increase in the number of suspension cells (Additional file 3: Figure S1). MDA-MB231 and MCF7 cells displayed a significant increase in the expression of marker genes for SS (Epcam and Egr1), stemness (Nanog and Oct4B), and EMT (N-Cadherin and Twist) (Fig. 2f). Moreover, these cells had decreased expression of epithelial marker (E-Cadherin and Cytokeratin-8) genes (Fig. 2f).

\section{+SS drives the conversion of primary breast cancer cells into $\mathrm{CD} 24^{\text {low }} / \mathrm{CD} 44^{\text {low }} / \mathrm{CD} 133^{\text {high }}$ TICs with elevated EMT marker expression}

To further demonstrate whether +SS simulated by repeated shaking and suspension promotes the acquisition of EMT potential among primary breast cancer cells, we harvested tumor cells (CT-PC) from primary sites in patients with advanced breast cancer who underwent neoadjuvant chemotherapy, and subjected cultures to LSS, OSS, and + SS (Fig. 3a). CT-PCs exposed to LSS showed a slight increase in the amount of suspension cells (Fig. 3b-i) and expression of SS-induced (Fig. 3b-ii), stemness marker (Fig. 3b-iii), or EMT marker (Fig. 3b-iv) genes. Moreover, these cells showed slight decrease in expression of epithelial marker (E-Cadherin and Cytokeratin-8) genes (Fig. 3b-v). Importantly, CT-PCs exposed to OSS, showed a significant increase in the number of suspension cells (Fig. 3c-i) and expression of SS-induced (Fig. 3c-ii), stemness factor (Fig. 3c-iii), and EMT marker (Fig. 3c-iv) genes, compared to cells not exposed to OSS. Furthermore, these cells showed significant decrease in expression of epithelial marker (E-Cadherin and Cytokeratin-8) genes (Fig. 3c-v). More importantly, CT-PCs exposed to + SS demonstrated a very significant increase in the number of suspension cells during 10-day culture (Fig. 3d), accompanied by substantial upregulation of SS-induced genes (Egr1, Epcam, and Klf8; Fig. 3e), stemness markers (Nanog, Sox2, and Oct4B; Fig. 3f), and multiple EMT markers, N-cadherin, Twist, Snail1, and Vimentin (Fig. $3 \mathrm{~g}$ ), compared with those cultured without shaking (-SS) and MDA-MB231 or MCF7 cells cultured under shaking (+SS in Fig. 2f). Upregulation of these stemness and EMT marker genes was evident from day 3 and plateaued by day 10 following application of + SS. Moreover, CT-PCs exposed to + SS showed significant decrease in expression of epithelial marker (E-Cadherin and Cytokeratin-8) genes (Fig. 3h). Furthermore, using western blot analysis, we confirmed the increased expression of EMT markers, TWIST and N-CADHERIN, and decreased expression of an epithelial marker, E-CADHERIN, in CT-PCs exposed to $+\mathrm{SS}$, compared with those cultured without shaking (-SS) (Fig. 3i). Additionally, CT-PCs exposed to +SS showed significant decrease in expression of $p 53$ and $p 21$ genes (Additional file 4: Figure S2). CT-PCs displayed a $\mathrm{CD} 24^{\text {middle }} / \mathrm{CD} 44^{\text {high }} / \mathrm{CD} 133^{\text {middle }}$ phenotype before $+\mathrm{SS}$. However, after 10 days of +SS culture, they exhibited a $\mathrm{CD} 24^{\text {low }} / \mathrm{CD} 44^{\text {low }} / \mathrm{CD} 133^{\text {high }}$ phenotype (Fig. 3j). 
a

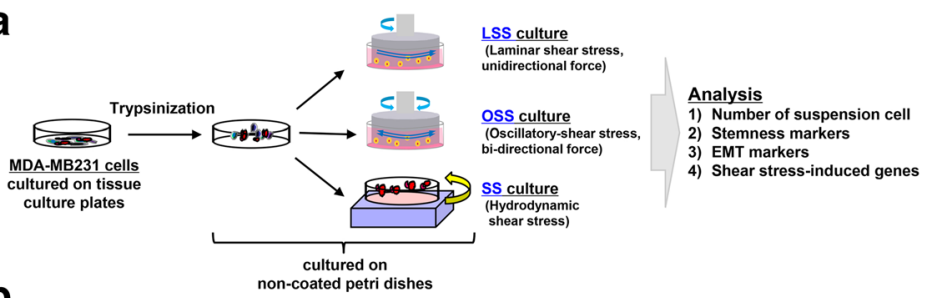

$b_{i}$
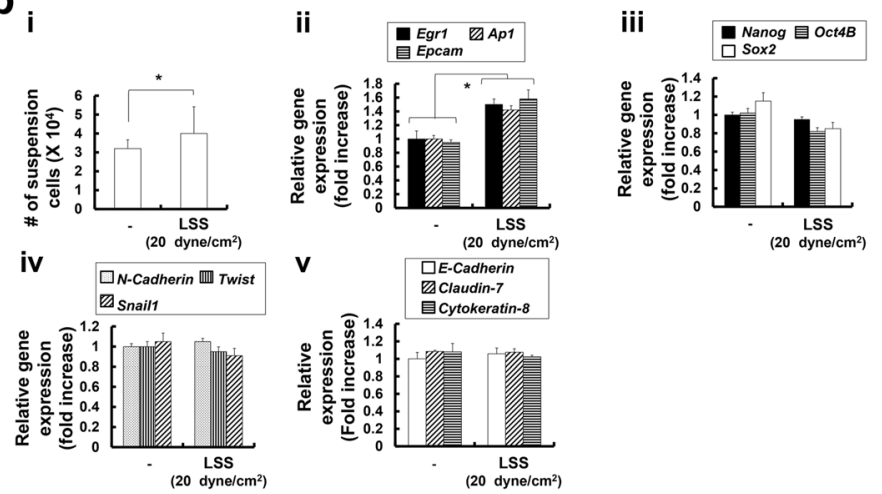

$c_{i}$

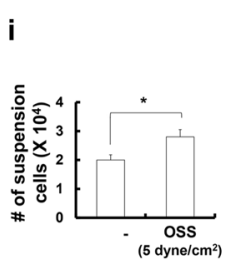

ii
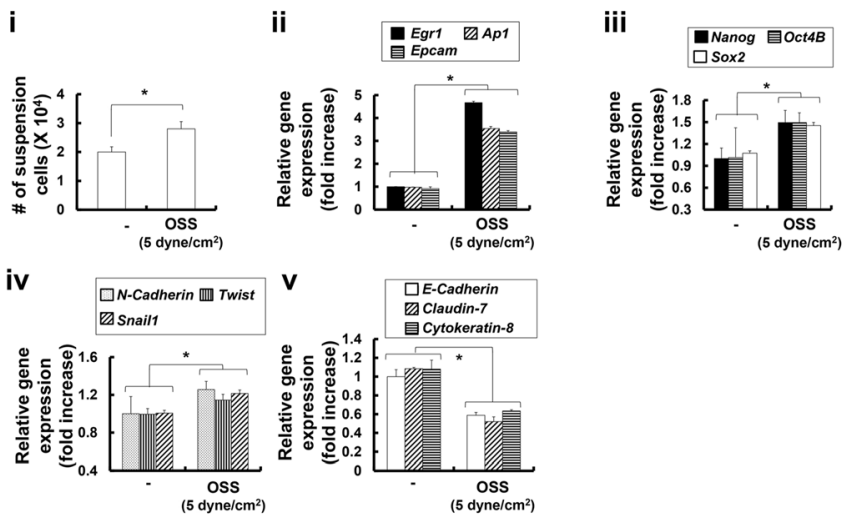

d

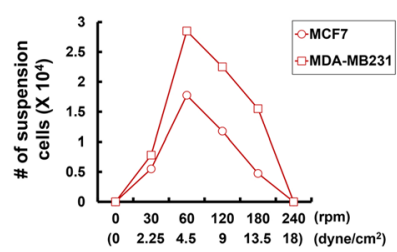

e
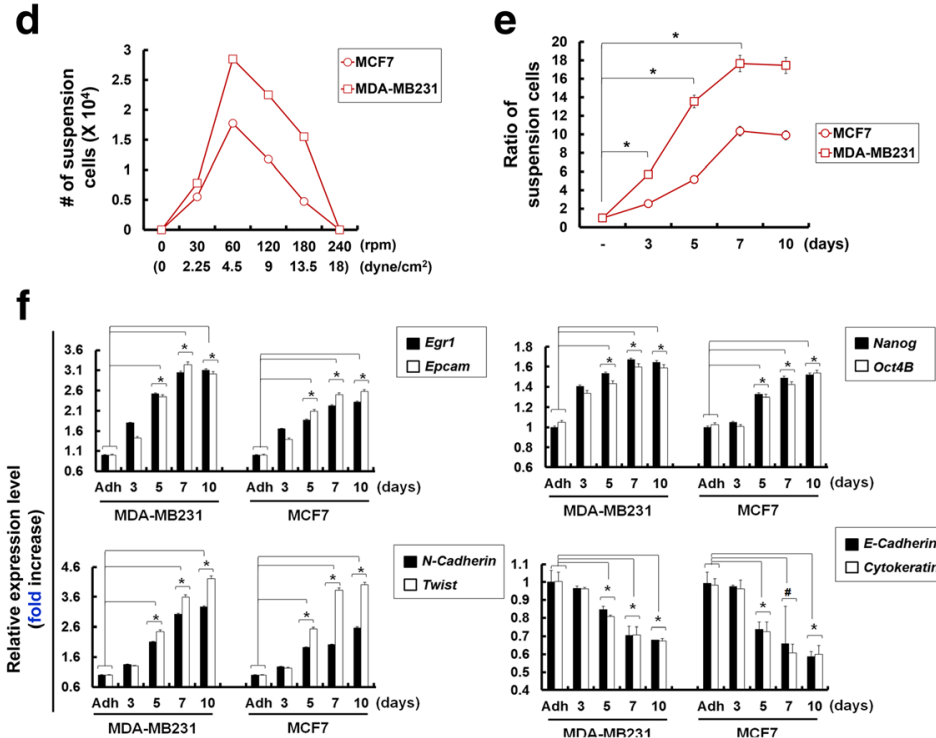
$\begin{array}{ccccc}\text { Adh } 3 \quad 5 \quad 7 \quad 10 & \text { Adh } 3 \quad 5 \quad 7 \quad 10 \\ \text { MDA-MB231 } & & \text { MCF7 }\end{array}$

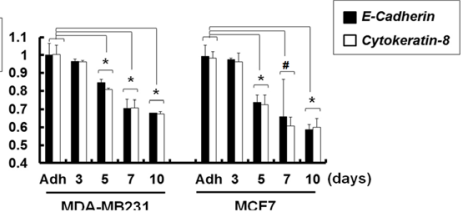

Fig. 2 (See legend on next page.) 
(See figure on previous page.)

Fig. 2 Hydrodynamic shear stress (SS) given as oscillatory shear stress (OSS) led to the acquirement of epithelial-mesenchymal transition (EMT) and stemness marker genes in MDA-MB231 cells. a Schematic illustration of in vitro fluid SS, including cone-and-plate viscometer-based laminar shear stress (LSS) or OSS and orbital shaker-based hydrodynamic SS. b (i) Number of suspension cells during LSS (270 rpm corresponds to 20 dyne $/ \mathrm{cm}^{2}$ ) conditions of MDA-MB231 cells in non-coated Petri dishes after $24 \mathrm{~h}$ of culture. Cell viability was measured by trypan blue exclusion assay and error bars represent \pm SD calculated from at least three independent experiments. Expression level of SS-induced (Egr1, Ap1 and Epcam (ii)), stemness marker (Nanog. Oct4B and Sox2; (iii)), EMT marker (N-Cadherin, Twist and Snail1; (iv)), and epithelial marker (E-Cadherin, Claudin-7, and Cytokeratin-8; (v)) genes in cells in suspension during LSS conditions of MDA-MB231 cells in non-coated Petri dishes, analyzed by quantitative real-time RT-PCR. c (i) Number of suspension cells during OSS (67 rpm corresponds to 5 dyne/ $\mathrm{cm}^{2}$ ) conditions in MDA-MB231 cells in non-coated Petri dishes after $24 \mathrm{~h}$ of culture. Expression level of SS-induced (Egr1, Ap1 and Epcam; (ii)), stemness marker (Nanog. Oct4B and Sox2; (iii)), EMT marker (N-Cadherin, Twist and Snail1; (iv)), and epithelial marker (E-Cadherin, Claudin-7, and Cytokeratin-8; v) genes in suspension cells during OSS conditions of MDA-MB231 cells in non-coated Petri dishes, analyzed by quantitative real-time RT-PCR analysis. $\mathbf{d}$ Number of suspension cells during +SS (30-240 rpm corresponds to 2.25-18 dyne/ $\mathrm{cm}^{2}$ ) conditions of breast cancer (MDA-MB231, MCF7) cells in non-coated Petri dishes after $24 \mathrm{~h}$ of culture. e Ratio of suspension cells in hydrodynamic SS (+SS) conditions (60 rpm corresponds to 4.5 dyne/ $\mathrm{cm}^{2}$ ) of the indicated cells in non-coated Petri dishes were assessed on day 3,5,7, and 10. Cell viability was measured by trypan blue exclusion assay and error bars represent \pm SD calculated from at least three independent experiments. $\mathbf{f}$ Expression of SS-induced (Egr1 and Epcam), stemness marker (Nanog and Oct4B), EMT marker (N-Cadherin and Twist), and epithelial marker (E-Cadherin, Claudin-7, and Cytokeratin-8) genes expressed in the indicated cells over time on the indicated days, analyzed by quantitative real-time RT-PCR; ${ }^{\#} p<0.05,{ }^{*} p<0.01$. Each gene expression in quantitative real-time RT-PCR analysis was normalized to Gapdh. The data presented here are presented as mean \pm SEM and are representative of three independent experiments. Statistically significant differences were tested at $p<0.05$ significance

\section{CT-PCs generated upon +SS (CT + SS) demonstrate significantly increased tumorigenicity in vivo}

To investigate the tumorigenic potential of $\mathrm{CT}+\mathrm{SS}$, NOD/SCID mice were injected subcutaneously with increasing numbers of CT + SS or CT-PCs, and tumor sizes were measured at 4 weeks post implantation (Fig. 4a). Compared with parental CT-PCs, CT + SS implanted into the mice grew faster and had larger volume and weight, and the tumors developed even with as few as 100 implanted cells (Fig. 4a). Moreover, immuno-histological examination revealed strong N-CADHERIN and TWIST expression and low E-CADHERIN expression in mice bearing CT + SS cells (Fig. 4a). To further evaluate the serial tumorigenic potential of CT $+\mathrm{SS}$ in vivo [41, 42], we subcutaneously injected 100 tumor cells derived from mice serially implanted with $\mathrm{CT}+\mathrm{SS}$ into secondary and tertiary recipient $\mathrm{NOD} / \mathrm{SCID}$ mice. $\mathrm{CT}+\mathrm{SS}$ harvested from the secondary recipient mice formed tumors with as few as 50 implanted cells (data not shown). Moreover, cells harvested from the tertiary recipient mice formed approximately sixfold larger and heavier tumors (Fig. 4b) and had higher N-CADHERIN and TWIST expression and lower E-CADHERIN expression (Fig. 4c) than cells harvested from the primary recipient mice, confirming the in vivo regenerative capacity of $\mathrm{CT}+\mathrm{SS}$.

We further investigated whether similar stemness features could be preserved when tumor cells were orthotopically transplanted. $\mathrm{GFP}^{+}$parental tumor (CT-PCs) or $\mathrm{GFP}^{+} \mathrm{CT}+\mathrm{SS}$ cells were injected into the mammary fat pads of NOD/SCID mice, and green fluorescence was monitored using bio-fluorescence imaging over time (Fig. 4d). After 4 weeks, tumor formation was evident in $\mathrm{CT}+\mathrm{SS}$-injected mice but not in CT-PC-injected mice. After 8 weeks, the number of $\mathrm{GFP}^{+}$cells increased significantly in $\mathrm{CT}+\mathrm{SS}$-injected mice compared with that in CT-PC-injected mice (Fig. 4d). Moreover, ionized calcium levels in the whole blood [14, 43], a measure of metastasis, were significantly increased in CT + SS-injected mice (Fig. 4e). Collectively, these data strongly indicate that $+\mathrm{SS}$ is important for inducing the conversion of epithelial tumor cells into CSLCs/ TICs with increased stemness and EMT marker expression, elevated sphere formation ability, and strong in vivo tumorigenicity.

\section{Increased ROS-responsive and NO-responsive gene transcription precedes the conversion of CT-PCs into $\mathrm{CT}+\mathrm{SS}$}

To understand molecular mechanism underlying the conversion of CT-PCs into CT $+\mathrm{SS}$, we compared the global gene expression patterns in $\mathrm{CT}+\mathrm{SS}$ with those in parental CT-PCs by performing RNA sequencing (RNA seq.). Heat map analysis and Gene Ontology (GO) data indicated that $\mathrm{CT}+\mathrm{SS}$ showed altered expression of proteins involved in cellular/metabolic processes (biological process) and signal transduction (molecular function) and upregulated expression of stemness, EMT, drug-resistance, and antioxidant genes (Fig. 5 a). Moreover, CT + SS showed significantly increased expression of SS-induced genes, including Epcam, Arg2, Cldn4, S100a14, Klf8, and Krt18 (Fig. 5b). Interestingly, these cells also showed upregulated expression of Aldh1, Cxcr4 and multidrug resistance genes, including $A b c g 2$, and $A b c b 5$ (Fig. 5c). Furthermore, $\mathrm{CT}+\mathrm{SS}$ showed robust chemo-resistance to doxorubicin and paclitaxel (Fig. 5d) and elevated migration and invasion capacities (Fig. 5e). A similar gene expression pattern with elevated migration and chemo-resistance properties was observed in MDA-MB231 cells cultured under +SS (data not 


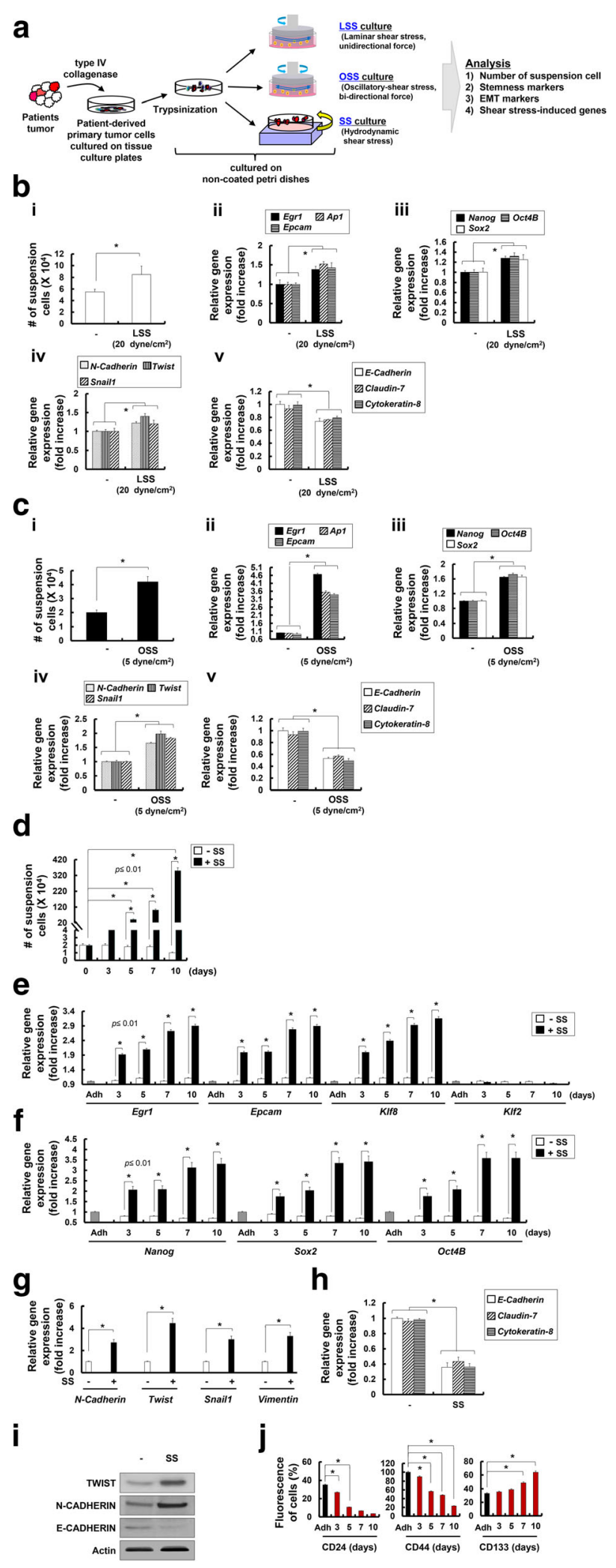

Fig. 3 (See legend on next page.) 
(See figure on previous page.)

Fig. 3 Hydrodynamic shear stress (+SS) given as orbital shaking led to the acquisition of epithelial to mesenchymal transition (EMT) and stemnessassociated genes in primary epithelial tumor cells isolated from patients with breast cancer. a Schematic illustration of the in vitro fluid SS (laminar SS (LSS), oscillatory SS (OSS), or SS) that was exposed to breast cancer cells derived from chemotherapy-treated patients (CT-PCS). CT-PCS (density, $2 \times 10^{5}$ cells) were isolated as described in "Methods" and subjected to cone-and-plate viscometer-based LSS or OSS and orbital shaker-based +SS in noncoated Petri dishes. b (i) Number of suspension cells during LSS (270 rpm corresponds to 20 dyne/ $\mathrm{cm}^{2}$ ) conditions of CT-PCs at $24 \mathrm{~h}$ was measured by trypan blue exclusion assay and error bars represent \pm SD calculated from at least three independent experiments. Expression level of SS-induced (Egr1, Ap1 and Epcam; (ii)), stemness marker (Nanog. Oct4B and Sox2; (iii)), and EMT marker (N-Cadherin, Twist and Snail1; (iv)), and epithelial marker (E-Cadherin, Claudin-7, and Cytokeratin-8; v) genes in suspension cells during LSS conditions of CT-PCs in non-coated Petri dishes, analyzed by quantitative real-time RT-PCR. c (i) Number of suspension cells during OSS (67 rpm corresponds to $5 \mathrm{dyne} / \mathrm{cm}^{2}$ ) conditions of CT-PCs in non-coated Petri dishes after $24 \mathrm{~h}$ of culture. Expression level of SS-induced (Egr1, Ap1 and Epcam; (ii)), stemness marker (Nanog. Oct4B and Sox2; (iii)), and EMT marker (N-Cadherin, Twist and Snail1; (iv)), and epithelial marker (E-Cadherin, Claudin-7, and Cytokeratin-8; (v)) genes in suspension cells during OSS conditions of CT-PCS in non-coated Petri dishes, analyzed by quantitative real-time RT-PCR analysis. $\mathbf{d}$ Number of cells in suspension without SS culture (-SS) or following SS culture (+SS) counted at 3, 5, 7, and 10 days using trypan blue exclusion assay. e-h Quantitative real-time RT-PCR analysis was performed on CT-PCs harvested at 3, 5, 7, and 10 days after culture to measure the expression of SS-induced (Egr1, Epcam, KIf8 and KIf2) (e), stemness marker (Nanog, Sox2, and Oct4B) (f), EMT marker (N-Cadherin, Twist, Snail1, and Vimentin) (g) and epithelial marker (E-Cadherin, Claudin-7, and Cytokeratin-8 (h) genes. i Western blot analysis was performed on CT-PCS (-) and CT-PCs harvested on 10 days after SS culture (SS) to detect the expression of EMT marker (TWIST and N-CADHERIN) and epithelial marker (E-CADHERIN) proteins. $\mathbf{j}$ Surface marker expression of CD24, CD44, and CD133 were analyzed using flow cytometry and presented as percentage (fluorescent ${ }^{+}$cells/all cells $\times 100 \%$ ). Expression of each gene in quantitative real-time RT-PCR analysis was normalized to Gapdh. The data are presented as mean \pm SEM and are representative of three independent experiments. Statistically significant differences were tested at $p<0.05$

shown). These data suggest that $+\mathrm{SS}$ allows CT-PCs to acquire TIC characteristics, with a distinct CD133 $3^{\text {high }}$ /CXCR $4^{\text {high }} / \mathrm{ALDH} 1^{\text {high }}$ phenotype.

Importantly, CT + SS showed increased transcription of ROS-responsive genes (Sod1, Cat, Nox1, Nox4, and Gpx1) and NO-responsive genes (Nos1, Nos2, and Noxtrin) (Fig. 6a-i and b-i). ROS functions in redox signaling and oxidative stress, which regulate diverse physiological parameters such as the growth factor stimulation and inflammatory response generation [44]. NO triggers a signaling pathway regulated by SS $[45,46]$ and hematopoiesis [47]. These results demonstrate that +SS can trigger generation of free radical species, such as ROS and reactive nitrogen species. To validate the results of RNA-seq., we measured intracellular ROS and $\mathrm{NO}$ levels in CT-PCs exposed to +SS. ROS level increased significantly in CT-PCs from day 3 of orbital shaking and remained elevated throughout the culture period (Fig. 6a-ii). This in turn activated ROS-responsive genes such as Sod1, Cat, Nox1 and Nox4 in CT-PCs from day 3 of repeated shaking (Fig. 6a-i). Treatment of $\mathrm{CT}+\mathrm{SS}$ with the ROS scavenger $\mathrm{N}$-acetylcysteine (NAC) suppressed ROS production (Fig. 6a-ii) and significantly reduced the number of proliferating CT-PCs (Fig. 6a-iii). NO content and NO-responsive gene (Nos1 and Nos2) expression also increased in CT + SS (Fig. 6b-i). Importantly, treatment of CT + SS with a NOS inhibitor N(G)-nitro-l-arginine-methyl ester (L-NAME) decreased intracellular NO level (Fig. 6b-ii), thus decreasing their proliferation (Fig. 6b-iii). These data demonstrate that ROS-induced and NO-induced transcriptional changes under +SS are critical upstream events for the conversion of CT-PCs into highly proliferating $\mathrm{CT}+\mathrm{SS}$.

\section{Active suppression of ERK and GSK3 $\beta$ activities is a prerequisite for the generation of highly tumorigenic $\mathrm{CT}+\mathrm{SS}$}

Recent studies indicate that self-renewal of embryonic stem (ES) cells is induced by the downregulation of ERK-associated differentiation-inducing signaling pathways [48, 49]. Consistently, our RNA-seq. data showed downregulation of ERK-related genes (Elk1, Ets1, Mcl1, Tp53, and Stat3) in CT + SS (Fig. 7a). Moreover, CT + SS showed a significant reduction in ERK phosphorylation (Fig. 7b) but did not show any change in p38 MAPK and JNK phosphorylation levels. Moreover, the sphere-forming capacity of CT + SS under + SS culture increased after treatment with an MEK inhibitor PD98059 (Fig. 7c). Inhibition of p38 MAPK activity by SB203580 or JNK activity by SP600125 did not affect the sphere-forming capacity of CT $+\mathrm{SS}$. To confirm the role of ERK in the conversion of CT-PCs into CT + SS, we introduced a FLAG-tagged WT MEK (WT-MEK) or constitutively active MEK (active-MEK) transgene into $\mathrm{CT}+\mathrm{SS}$ (Fig. 7d). CT + SS overexpressing active-MEK showed a significant increase in MEK and ERK phosphorylation, which increased p53 and p21 expression (Fig. 7d). Furthermore, CT + SS overexpressing active-MEK showed dramatically reduced sphere formation capacity (Fig. 7e) and decreased stemness factors (Nanog, Oct4B, and Sox2) and drug resistance gene (Aldh1, Abcg2, and Abcb5) expression (Fig. 7f) compared with mock-transfected or WT-MEK-overexpressing cells. Importantly, CT + SS overexpressing active-MEK showed significantly decreased tumorigenicity in vivo (Fig. 7g) compared with mock-transfected or WT-MEK-overexpressing cells. These results confirm that suppression of the ERK pathway is critical 
a
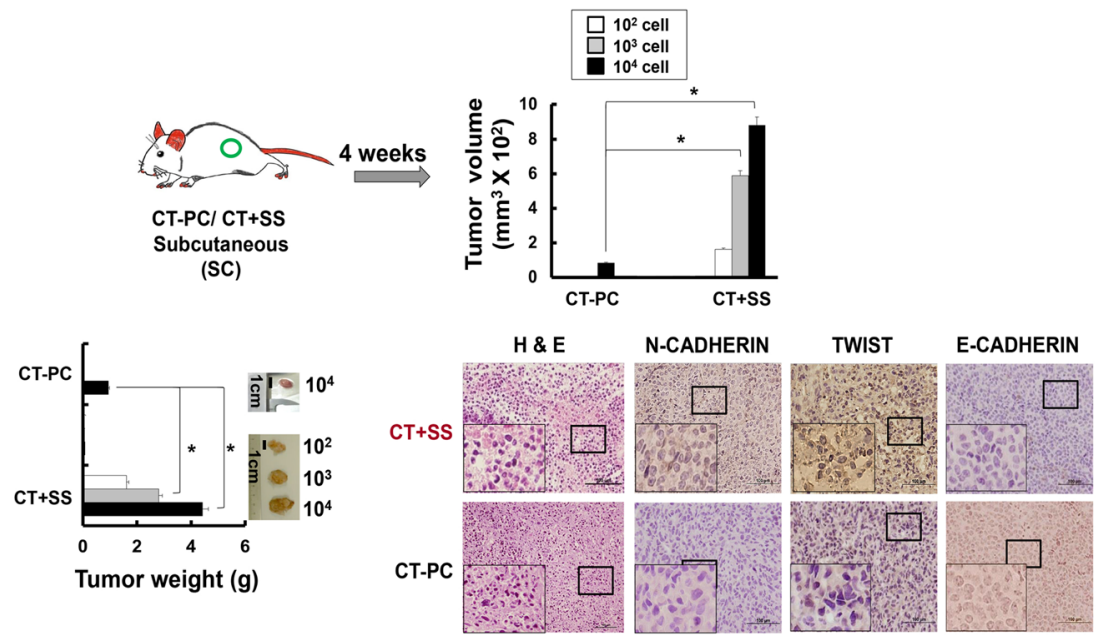

b

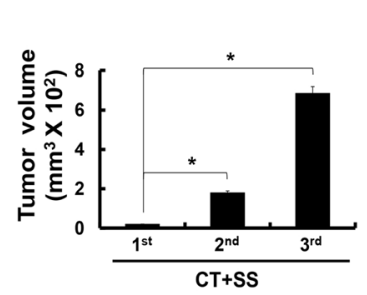

C

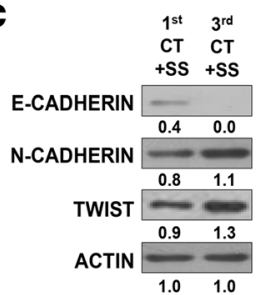

d

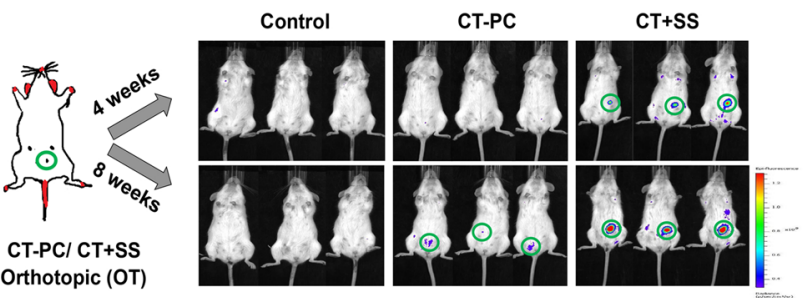

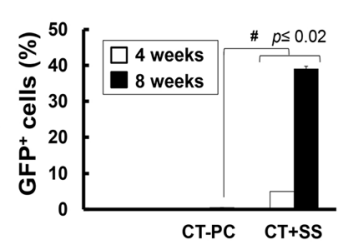

$\mathbf{e}$

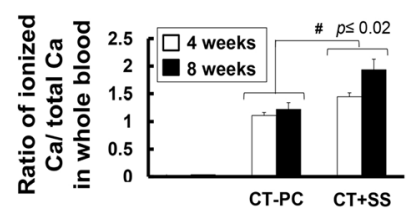

Fig. 4 Patient-derived primary epithelial tumor cells cultured under hydrodynamic stress (SS) demonstrate significantly elevated in vivo tumorigenicity. a NOD/SCID mice were injected subcutaneously with increasing numbers of breast cancer cells derived from chemotherapy-treated patients CT-PCs or $\mathrm{CT}+\mathrm{SS}$, and tumor volumes (middle panel) and weights (right panel) were measured at 4 weeks after tumor cell inoculation. Representative images of tumors from the mice injected with the indicated number of cells $\left(10^{2}-10^{4}\right.$ cells per site) are shown on the right $\left(n=3,{ }^{*} p<0.05\right)$. Tumor tissues from the CT + SS-injected mice were analyzed by H\&E staining or immunohistochemical analysis with the indicated antibody. Each indicated region (small squares) is magnified in the insets. $\mathbf{b}$ Tumor volumes and weights of successive passages of xenografts harboring CT + SS. The secondary xenograft was generated from injection of 50 cells isolated from the tumors formed from the preceding passage. Representative images of tumors harvested from mice are shown on the right $\left(n=4,{ }^{*} p<0.05\right)$. c Protein expression of E-CADHERIN, N-CADHERIN, and TWIST was analyzed by western blot using the tumor tissues harvested from the $1^{\text {st }}$ and $3^{\text {rd }}$ passaged mice. Numbers refer to the densitometry analysis of each signal normalized against the corresponding anti-ACTIN values. $\mathbf{d}$ In vivo tumorigenicity of NOD/SCID mice injected orthotopically into the mammary fat pads with CT-PCs or CT + SS. Left panel, representative BFI images of mice at 4 and 8 weeks post-injection of the indicated cells $(n=3)$. Right panel, the percentage of green fluorescent protein (GFP) ${ }^{+}$cells in the blood at 4 and 8 weeks post-injection was analyzed by flow cytometry. e The ratio of ionized calcium levels in whole blood from the CT-PCS- or CT + SS-injected mice were measured by the ABL800 analyzer. Error bars correspond to mean $\pm \mathrm{SD}$. Statistically significant differences were tested at $p<0.05$ 


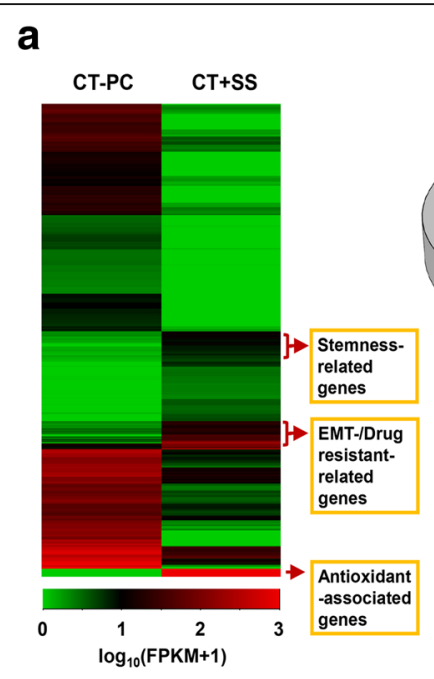

b

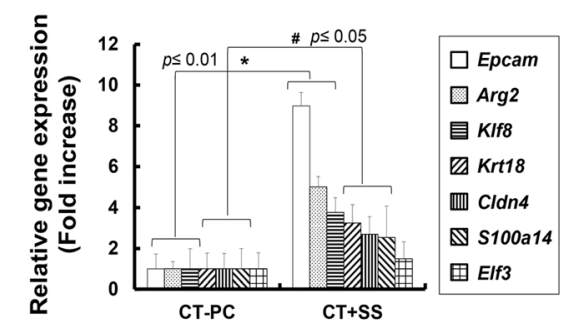

d

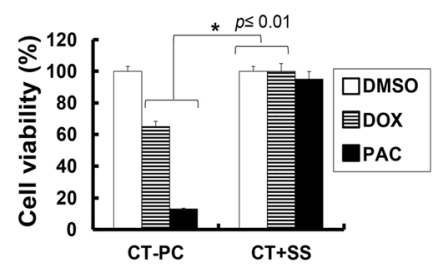

Biological process

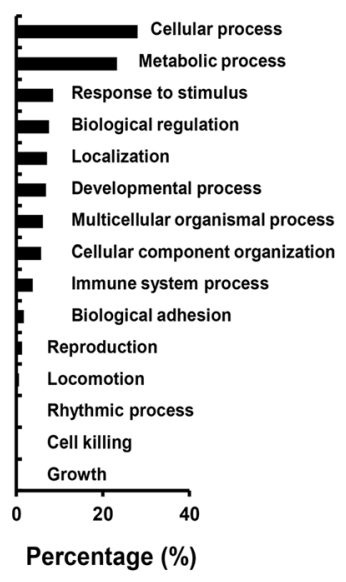

C

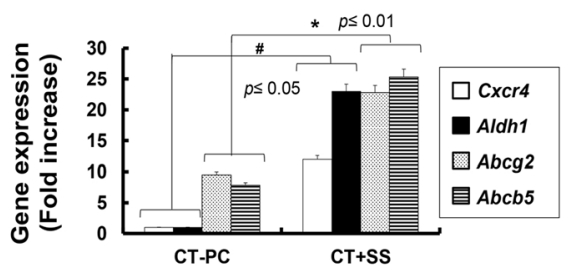

e

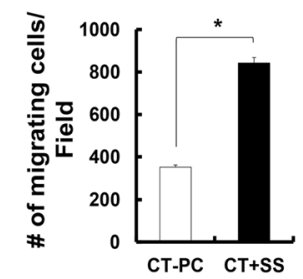

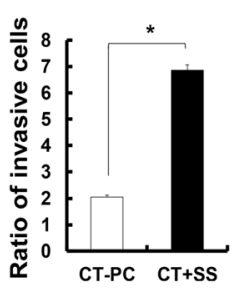

Fig. 5 Patient-derived primary epithelial tumor cells acquire chemo-resistance with elevated migration and invasive potentials upon repeated orbital shaking. a Heatmap represents relative expression levels of genes showing least twofold difference between breast cancer cells derived from chemotherapy-treated patients (CT-PC) and CT + sheer stress (SS) with a $p$ value $<0.05$ is shown. Red and green represent the highest and lowest value of each gene analyzed, respectively. Gene Ontology (GO) analysis of RNA sequencing data revealed differential molecular function and biological processes on CT + SS compared with CT-PCS. GO categories for genes using the Network Ontology Analysis program (http:// www.pantherdb.org/). RNA seq analysis of CT-PCs and CT-PCs under orbital shaking (CT + SS) for 10 days revealed upregulation of multiple SSinduced genes; Epcam, Arg2, Cldn4, S100a14, Klf8, and Krt18 (b) and multi-drug resistance genes; Cxcr4, Aldh1, Abcg2, and Abcb5 (c) upon +SS ( $p$ value compared with the non-shaking control group). $\mathbf{d}$ Cell viability of CT-PCS and CT + SS following treatment with doxorubicin or paclitaxel for $24 \mathrm{~h}$ ( $p$ value compared with dimethyl sulfoxide (DMSO)-treated cells). e Migration analysis was performed on CT-PCs and CT + SS by measuring the number of migrating cells per field of the wound made in the monolayer of cells. The migrating or invasive cells were measured in triplicate. Statistically significant differences were tested at $p<0.05$

for acquiring and maintaining CSLCs/TICs properties of CT + SS in vivo.

Recent studies demonstrate that downregulation of ERK activity is critical for the self-renewal of embryonic stem (ES) cells because ERK triggers the differentiation of these cells $[48,49]$. Moreover, GSK3 $\beta$ inhibition consolidates biosynthetic capacity and suppresses residual differentiation [48]. Therefore, we examined whether $\mathrm{CT}+\mathrm{SS}$ had a similar signaling cascade as that observed in ES cells by downregulating GSK3 $\beta$. Indeed, we found that inhibitory phosphorylation at Ser9 position of GSK3 $\beta$ was increased in CT + SS (Fig. 7h), implying that GSK3 $\beta$ activity was suppressed in CT + SS upon +SS. Consistently, CT-PCs under + SS had increased sphere formation capacity after treatment with GSK3 $\beta$ inhibitor BIO (Fig. 7i). Furthermore, co-treatment of CT + SS with the MEK inhibitor, PD98059 and GSK3ß inhibitor, BIO, synergistically increased their sphere formation capacity 
a

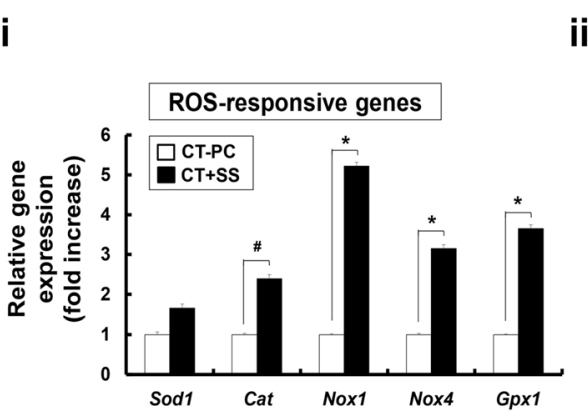

iii

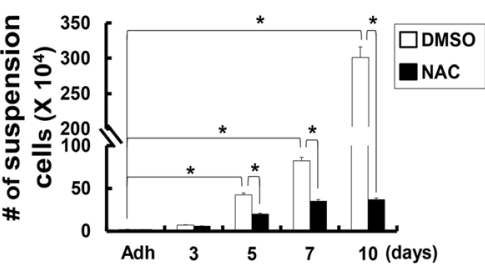

b

i

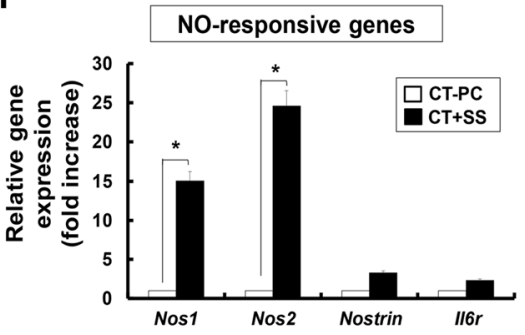

iii

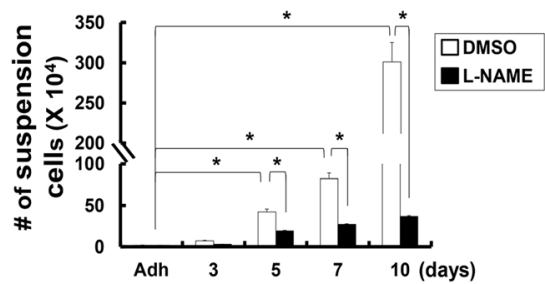

Fig. $6 \mathrm{CT}$ + shear stress (SS) demonstrate upregulation of reactive oxygen species (ROS)-responsive and nitric oxide (NO)-responsive genes. a Transcriptional profile of the selected ROS-responsive genes (Sod1, Cat, Nox1, Nox4, and Gpx1; i). (ii) Flow cytometry analysis of ROS generation of breast cancer cells derived from chemotherapy-treated patients (CT-PCs) treated with N-acetylcysteine (NAC) on day 3, 5, 7, and 10 during +SS ( $p$ value compared with adherent cells). iii, The number of suspended cells was counted on day 3, 5, 7, and 10 in the presence or absence of NAC treatment. b Transcriptional profile of the selected NO-responsive genes (Nos1, Nos2, and Noxtrin; (i)). Intracellular NO analysis was performed on CT-PC and CT + SS with $1 \mathrm{mM} \mathrm{N(G)-nitro-l-arginine-methyl} \mathrm{ester} \mathrm{(L-NAME)} \mathrm{by} \mathrm{measuring} \mathrm{the} \mathrm{fluorescence} \mathrm{NO} \mathrm{probe} \mathrm{(ii).} \mathrm{The} \mathrm{number} \mathrm{of}$ suspended cells was counted on day 3,5, 7, and 10 in the presence or absence of L-NAME (iii). The data presented here are presented as mean \pm SEM and are representative of three independent experiments. Statistically significant differences were tested at $p<0.05$

(Fig. 7i) and stemness factor (Nanog, Oct4B, and Sox2; Fig. 7j) and EMT marker (Snail, Twist, and N-Cadherin; Fig. 7k) expression. Consistently, we found that co-treatment of CT + SS with PD98059 and BIO synergistically increased both messenger RNA (mRNA) and protein expression of EMT marker (TWIST and N-CADHERIN) genes while decreasing that of epithelial markers (E-Cadherin, Claudin-7, and Cytokeratin-8)
(Fig. 7l). Taken together, these data indicate that downregulation of ERK and GSK3 $\beta$ activities in CT + SS is critical for maintaining their EMT potential and tumorigenicity under + SS.

\section{Discussion}

EMT contributes to the early-stage dissemination of primary tumors and is a prerequisite for the invasion and 
a

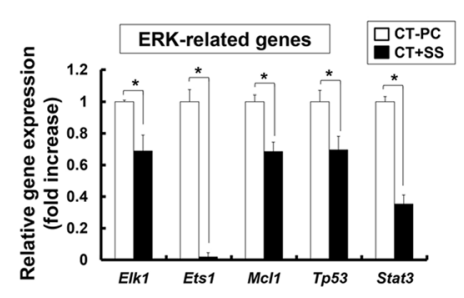

C

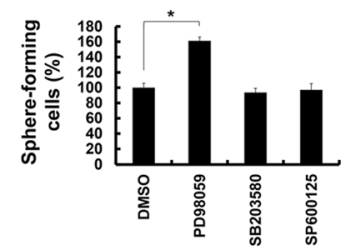

e

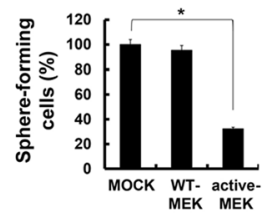

g

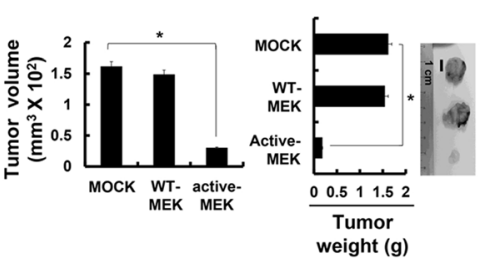

h
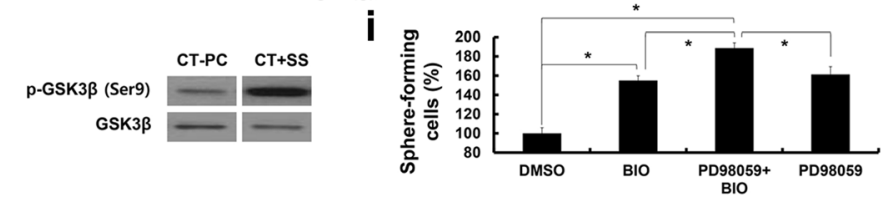

j

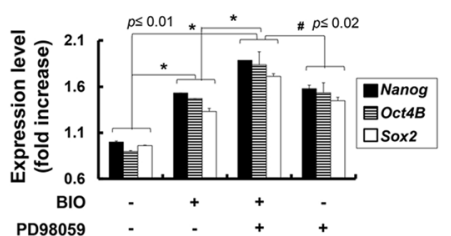

$\mathbf{k}$

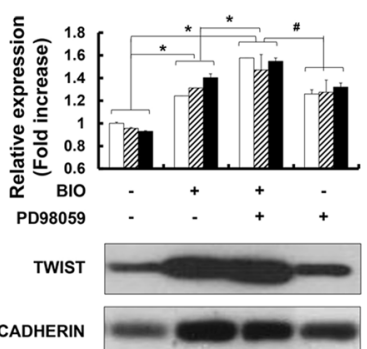

$$
1
$$

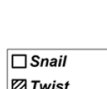

Twist

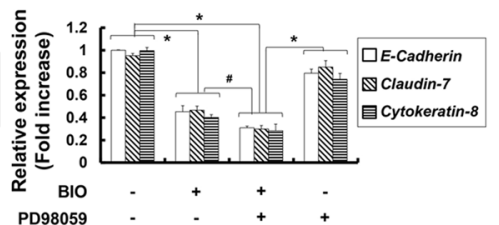

E-CADHERIN

ACTIN

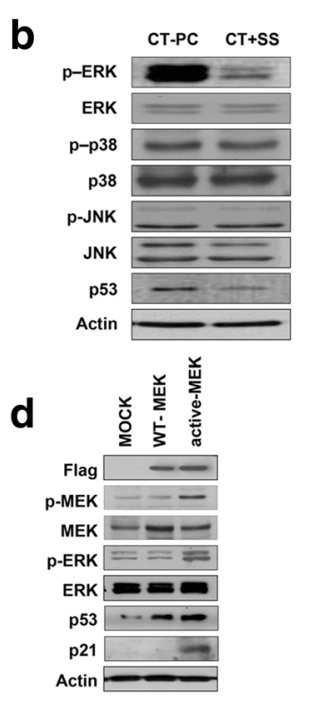

Nanog $\square$ Oct4B $\square$ Sox2 目Aldh1 $\square$ Abcg2 $\square$ Abcb5
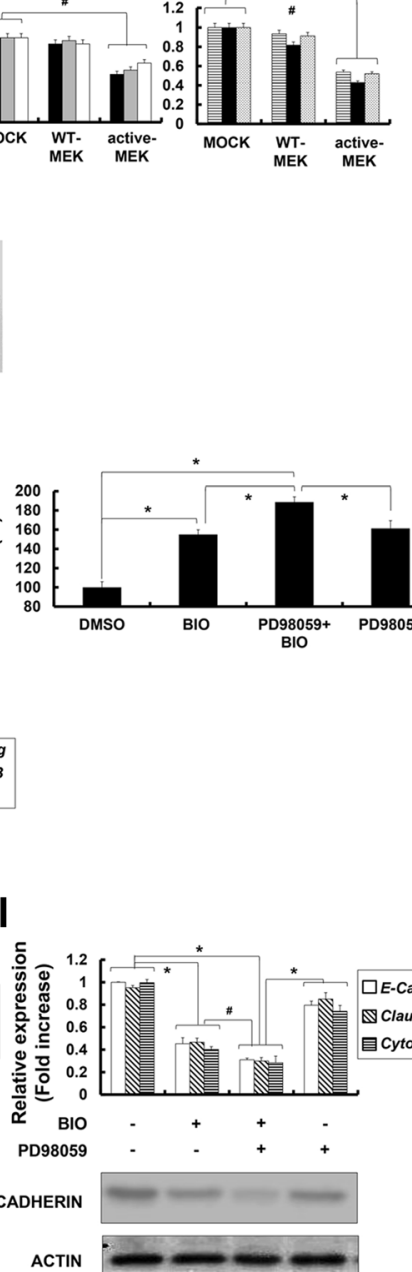

Fig. 7 (See legend on next page.) 


\section{(See figure on previous page.)}

Fig. 7 Downregulation of the extracellular signal-related protein kinase (ERK) pathway is critical for the conversion of breast cancer cells derived from chemotherapy-treated patients (CT-PCS) into $C T$ + shear stress (SS) displaying cancer stem-like cell (CSLC)/tumor-initiating cell (TIC) properties. a Transcriptional profile of the selected ERK-related genes (Elk1, Ets1, Mcl1, Tp53, and Stat3). b Western blot analysis of p-ERK, ERK, p-p38, p38, p-JNK, JNK, and p53 from CT-PCs or CT + SS (10 days) n. c CT-PCs under +SS for 3 days were treated with PD98059 (mitogen-activated protein kinase (MEK) inhibitor), SB203580 (p38 MAPK inhibitor), and SP600125 (JNK inhibitor) for $24 \mathrm{~h}$ and subjected to sphere-formation assay (* $p<0.01$ compared with dimethyl sulfoxide (DMSO)-treated cells). Error bars represent \pm SD from the three independent experiments. $\mathbf{d} C T+$ SS obtained from 3-day culture under +SS were transfected with Flag-tagged wild-type MEK (WT-MEK) or active MEK (active-MEK), and the level of Flag, p-MEK, MEK, p-ERK, ERK, p53, and p21 were assessed by western blot. e Changes in the number of sphere-forming cells in WT-MEK or active-MEK-expressing CT-PCs are shown as percent changes (\%) ( ${ }^{*} p<0.01$, compared to mock transfection). f Relative changes in the expression of self-renewal marker (Nanog, Oct4B, and Sox2) and multi-drug resistance (Aldh1, Abcg2, and Abcb5) genes are normalized to Gapdh. Data represent mean \pm SD from three independent experiments $\left({ }^{*} p<0.01\right)$. $\mathbf{g}$ In vivo tumorigenicity of mock, WT-MEK, and active-MEK carrying CT $+S S$ implanted subcutaneously on NOD/SCID mice. Tumor volumes and weights were measured in NOD/SCID mice after inoculation with $2 \times 10^{5}$ cells for 4 weeks. $\mathbf{h}$ Western blot analysis of $\mathrm{p}$-GSK3 $\beta$ and GSK3 $\beta$ from CT-PCs or suspension CT + SS are shown. CT-PCs under +SS for 3 days were treated with PD98059 (MEK inhibitor) or/and BIO (GSK3 $\beta$ inhibitor) for $24 \mathrm{~h}$ and subjected to sphere-formation assay (i), quantitative real-time RT-PCR ( $\mathbf{j}$ and upper panels of $\mathbf{k}$ and $\mathbf{I}$ ), or western blot (lower panels of $\mathbf{k}$ and $\mathbf{I}$ ) analyses of stemness (Nanog, Oct4B, and Sox2; j, EMT (Snail, Twist, and N-Cadherin (k)), and epithelial (E-Cadherin, Claudin-7, and Cytokeratin-8; I) marker genes. Relative changes in the expression of stemness and EMT marker genes are normalized to Gapdh; ${ }^{*} p<0.01$, Error bars correspond to mean \pm SD

metastasis of breast cancer cells. However, the importance of EMT in vivo is constantly under debate because metastatic lesions mostly exhibit epithelial phenotypes, presumably generated by MET, and that finding mesenchymal types of tumor cells from neighboring stromal cells has been difficult [50]. In fact, recent studies have challenged the current dogma by demonstrating that EMT may not be a prerequisite for metastasis [51, 52]. Cell lineage tracing studies indicate that metastatic tumor cells found in the lungs of MMTV-PyMT mice maintained their breast epithelial phenotype, suggesting that tumors of epithelial origin can enter nearby blood vessels without a pre-EMT requirement, migrate through the systemic circulation, and form secondary nodules in distant organs. The precise mechanism underlying these events is still not fully understood. However, our data provide evidence that + SS plays an important role in promoting the survival of circulating epithelial tumor cells by inducing lineage plasticity, which is characterized by the upregulated expression of stemness, EMT and epithelial markers (summarized in Fig. 8). Orbital shaking + SS or OSS, which may mimic arterial and venous circulation, sufficiently triggers this phenotypic transition in epithelial tumor cells. We demonstrate that $+\mathrm{SS}$-exposed cells acquire stem-like properties and become CSLCs/TICs and that this +SS-induced TIC formation is dependent on the generation of ROS and NO, accompanied by downregulation of the ERK and GSK3 $\beta$ pathways.

During metastasis, tumor cells are exposed to mechanical forces induced by fluid SS, hydrostatic pressure, and tension. To enter the vascular microenvironment, cancer cells penetrate surrounding tissue and enter nearby blood and lymphatic vessels. Interstitial flow is the slow movement of fluid around the cells and through the pores of the ECM that comprise the interstitium. One of the main functions of interstitial flow is lymphatic drainage, which returns plasma from leaky capillaries back to the bloodstream. The velocities of interstitial flows are believed to range from 0.1 to $1.0 \mu \mathrm{m} / \mathrm{sec}$ in normal tissues. Hemodynamic shear forces in the bloodstream range from 0.5 to 4.0 dyne $/ \mathrm{cm}^{2}$ in the venous circulation and 4.0 to 30.0 dyne $/ \mathrm{cm}^{2}$ in arterial circulation. Cancer cells are primarily exposed to erythrocytes, leukocytes, and platelets upon entering the bloodstream, as studies have shown that in patients the concentration of cancer cells in the blood is on the order of one in a million leukocytes, or one in a billion blood cells. These hemodynamic shear stresses and velocities can affect the viability and metastatic potential of cancer cells. A recent study revealed that the fluid SS $\left(0.05 \mathrm{dyne} / \mathrm{cm}^{2}\right)$, which may correspond to the velocity of fluid flow in the interstitium, can promote cancer motility through modulating the Yes-associated protein (YAP1)-related ROCK-LIMK-cofilin signaling pathway [53]. Another recent study has demonstrated that circulation of hematopoietic stem cells can trigger the onset of hematopoiesis and embryogenesis [18]. The fluid SS (5 dyne $/ \mathrm{cm}^{2}$ ) was shown to increase the expression of Runx1 in $\mathrm{CD}_{4} 1^{+} \mathrm{c}-\mathrm{Kit}^{+}$hematopoietic progenitor cells with concomitant augmentation of their hematopoietic colony-forming potential. Our data showed that the +SS $\left(4.5\right.$ dyne $\left./ \mathrm{cm}^{2}\right)$, which may mimic the hydrodynamic SS in the blood flow in the arterial vasculature, can trigger transition of epithelial breast tumor cells into stem-like CSLCs/TICs by upregulating stemness factor along with EMT factors primarily through modulation of ROS and NO generation, accompanied by downregulation of the ERK and GSK3 $\beta$ pathway. In our study, we could not detect significant increase in expression of YAP1 or Runx1 (data not shown). Although the detailed mechanism may be different, our data revealed that biomechanical forces appeared to be important micro-environmental factors that not only drive hematopoietic development but also lead to acquisition of CSLCs/TICs potential in cancer metastasis. 


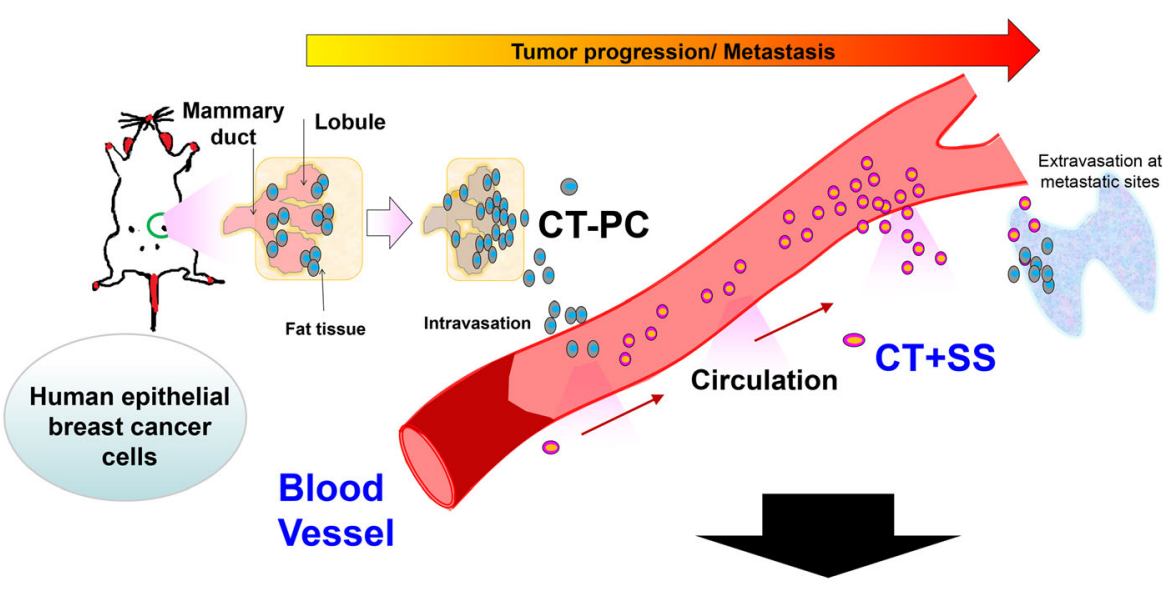

Hydrodynamic Shear Stress
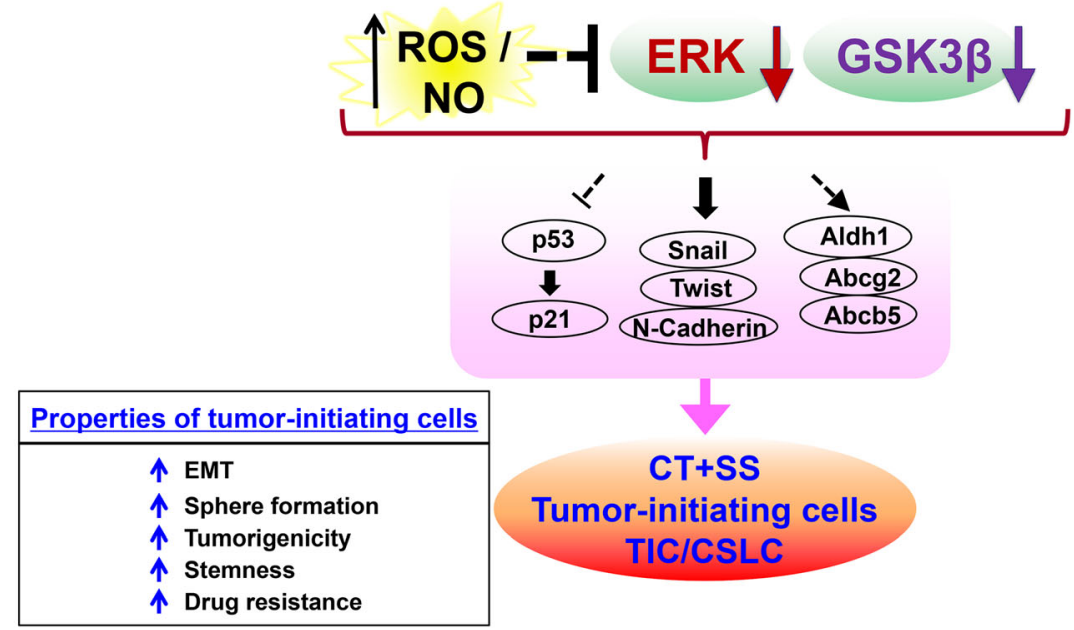

Fig. 8 Role of the hydrodynamic shear stress (+SS) in the conversion of epithelial tumor cells into cancer stem-like cells (CSLCS)/tumor-initiating cells (TICS). Proliferating tumor cells near the periphery of solid tumor mass are translocated into nearby blood vessels due to the nature of loose mosaic vessels. Once translocated into blood vessels, epithelial tumor cells are constantly exposed to severe SS in the systemic circulation and prone to dying in the absence of a strong survival signal. +SS given to tumor cells generate reactive free radial species, reactive oxygen species (ROS) and nitric oxide (NO), and cause transcriptional changes in ROS-dependent and NO-dependent pathways along with multiple SS-associated gene pathways. These early signaling events lead to active suppression of extracellular signal-related protein kinase (ERK) and glycogen synthase kinase (GSK) $3 \beta$ pathways to confer plasticity on the epithelial tumor cells, and maintain undifferentiated mesenchymal stem cell properties. As a result, tumor cells acquire survival benefit within the blood circulation with elevated stemness, Epithelial to mesenchymal transition (EMT)/ mesenchymal to epithelial transition (MET) properties, invasive properties, and multi-drug resistance phenotype. CT-PCs, breast cancer cells derived from chemotherapy-treated patients

Interestingly, we found that the majority of $\mathrm{CD} 24^{\text {mid- }}$ dle $/ \mathrm{CD} 44^{\text {high }} / \mathrm{CD} 133^{\text {middle }} / \mathrm{CXCR} 4^{\text {low }} / \mathrm{ALDH} 1^{\text {low }}$ primary parent tumor cells (CT-PCs) were converted to $\mathrm{CD} 24^{\text {low }} / \mathrm{CD} 44^{\text {low }} / \mathrm{CD} 133^{\text {high }} / \mathrm{CXCR} 4^{\text {high }} / \mathrm{ALDH} 1^{\text {high }}$

TICs under +SS in vitro. Since expressions of CD133, CXCR4, and ALDH1 have been associated with multiple chemo-resistance $[54,55]$, acquisition of resistance to doxorubicin and paclitaxel in our CT + SS is due to upregulation of these genes upon $+\mathrm{SS}$. Moreover, the fact that tumor cells introduced into the artery directly through intra-cardiac injection demonstrated higher stemness and EMT/MET potentials than those locally introduced into the mammary fat pads, further highlighting the importance of hydrodynamic force as a facilitator of CSLCs/TIC conversion. Upon serial passaging in vivo, $\mathrm{CT}+\mathrm{SS}$ tumor cells obtained by $+\mathrm{SS}$ acquired cancer stem-like properties, showing tumor development with only 50 cells implanted.

CT-PCs converted to TICs could acquire SS-induced genes, such as Egr1, Ap1, Epcam, Jun, and several Klf family genes, upon +SS application, suggesting that stress-responsive signaling pathways are hypersensitive 
in CT + SS cells compared with their parental tumor cells. SS-inducible genes such as the Egrl drive expression of Ap1, a transcription factor composed of protein dimers of c-JUN and c-FOS, which contributes to EPCAMdependent breast cancer invasion [56]. KLF8, which was also induced by SS, is expressed in several human cancers and is known to repress E-Cadherin transcription, thereby augmenting the motility and invasiveness of cancer cells [35]. Taken together, our findings suggest that upregulation of these stress-responsive genes may trigger the transition from primary parental tumor cells to more highly invasive tumor-initiating cells.

It is notable that the shear stress-dependent TIC formation of breast tumor cells depends on ROS/NO generation and downregulation of the ERK and GSK3 $\beta$ pathways. Activation of ERK/MAPK pathways is a key event in cell proliferation and tumor progression, that occurs downstream of pathways associated with several growth factors including EGF, PDGF, VEGF, FGF, and insulin, etc. [57-62]. Therefore, it was surprising to find that in this study TIC conversion required suppression of ERK activation. However, recent reports show that self-renewal of ES cells does not require growth factor signaling, but is enabled solely by downregulation of differentiation-inducing signaling pathways mediated by MAPK $[48,49]$. Additionally, inhibition of GSK3 $\beta$ consolidates biosynthetic capacity and suppresses residual differentiation. ES cells cultured in defined medium with inhibitors of two kinases (MEK and GSK3ß), a condition known as "2i", are thought to represent a naive ground state of ES cells. Since, we also observed downregulation of GSK3 $\beta$ activities by increased p-GSK3 $\beta$ (Ser9) in CT $+\mathrm{SS}$ cells and upregulation of $\mathrm{Wnt} / \beta$-catenin signal pathways, stemness of CT + SS cells appeared to be actively maintained by "2i" states. Therefore, the ERK inhibition seen in CT + SS cells cultured under orbital shaking may establish conditions required to maintain their stem-like ground states by active suppression of ERK, similar to that operating in ES cells. Furthermore, orbital shaking of primary tumor cells facilitated gradual loss of $p 53$, one of the driver genes mutated in tumor progression [63]; accumulation of WT $p 53$ in the nucleus causes direct inhibition of Nanog expression in mouse ES cells [64] and suppression of $p 53$ expression leads to de-repression of Nanog, which is required for maintenance of mouse ES cell self-renewal. Although detailed mechanisms of epithelial-TIC conversion by hydrodynamic forces awaits more thorough biochemical investigation, $p 53$ loss in TICs may affect upregulation of Nanog and other self-renewal marker genes.

\section{Conclusions}

We provide both in vivo and in vitro evidence that the conversion from epithelial tumor cells into specific high sphere-forming CD2 $4^{\text {low }} / \mathrm{CD} 44^{\text {low }} / \mathrm{CD} 133^{\text {high }} / \mathrm{CXCR} 4^{\text {high }} /$ ALDH $1^{\text {high }}$ CSLCs/TICs can occur upon hydrodynamic shear stress experienced during systemic circulation and the conversion is dependent on $\mathrm{ROS} / \mathrm{NO}$ generation and suppression of ERK/GSK3 $\beta$, a mechanism similar to that operating in embryonic stem cells to prevent their differentiation while promoting self-renewal. Our data highlight previously neglected "shear stress" forces as a critical factor in promoting the conversion of circulating tumor cells to CSLCs/TICs within the blood circulation and, in endowing the plasticity required for epithelial tumor cells to maintain self-renewal signaling pathways.

\section{Additional files}

Additional file 1: Table S1. Clinical characteristics of the patients with breast cancer in this study. (PDF $39 \mathrm{~kb}$ )

Additional file 2: Table S2. Sequences of the primers used in this study. (PDF $20 \mathrm{~kb}$ )

Additional file 3: Figure S1. The number of suspension cells during + SS conditions of hepatic, colon, and pancreatic cancer cell lines were assessed. Left panel, number of suspension cells during +SS (30-240 rpm corresponds to $2.25-18 \mathrm{dyne} / \mathrm{cm}^{2}$ ) conditions of hepatic cancer (SNU447, HepG2), colon cancer (HCT116, HT29), and pancreatic cancer (Panc2, Capan1) cells in non-coated Petri dishes were shown after $24 \mathrm{~h}$ of culture. Right panel, ratio of suspension cells +SS conditions (60 rpm corresponds to $4.5 \mathrm{dyne} / \mathrm{cm}^{2}$ ) conditions of indicated cells in non-coated Petri dishes were assessed on day 3, 5, 7, and 10. (PDF $81 \mathrm{~kb}$ )

Additional file 4: Figure S2 Quantitative real-time RT-PCR analysis was performed on indicated cells, at days indicated, to measure the expression of $p 53$ and $p 21$ genes expressed in the indicated cells over time; ${ }^{*} p<0.01$. (PDF $36 \mathrm{~kb}$ )

\section{Abbreviations}

AP1: Activator protein 1; CLSC: Cancer-like stem cell; CTC: Circulating tumor cell; CT-PCs: Breast cancer cells derived from chemotherapy-treated patients; DMEM: Dulbecco's modified Eagle's medium; DMSO: Dimethyl sulfoxide; ECM: Extracellular matrix; EGR1: Early growth response protein 1;

EMT: Epithelial to mesenchymal transition; EPCAM: Epithelial cell adhesion molecule; ERK: Extracellular signal-related protein kinase; ES: Embryonic stem; FBS: Fetal bovine serum; GFP: Green fluorescent protein; GO: Gene Ontology; GSK: Glycogen synthase kinase; H\&E: Hematoxylin and eosin; JNK: c-Jun N-terminal kinase; KLF8: Kruppel-like factor 8; LSS: Laminar shear stress; MAPK: Mitogen-activated protein kinase; MET: Mesenchymal to epithelial transition; MSC: Mesenchymal stem cell; NAC: N-acetylcysteine; NO: Nitric oxide; OSS: Oscillatory shear stress; OT: Orthotopical; PBS: Phosphatebuffered saline; RBC: Red blood cells; ROS: Reactive oxygen species; SS: Shear stress; TIC: Tumor-initiating cell; WT: Wild-type

\section{Acknowledgements}

We thank the members of all laboratories involved, for comments and suggestions.

\section{Funding}

This work was supported by the grants of the National Research Foundation (NRF) funded by the Korean government (2013M3A9D3045880, 2015R1A5A1009701, and 2017M3A9C602956 (SG Cho) and NRF2017R1A2B3004828 (KM Lee).

Availability of data and materials

All data needed to evaluate the conclusions in the paper are presented in the paper and/or Additional file 1. 


\section{Authors' contributions}

SGC, KML, and HYC designed the experiments. HYC, GMY, KK, YY, AAD, SKS, and $\mathrm{KH}$ performed experiments (provided animals acquired and managed patients, provided facilities, etc.). HYC, GMY, and SGC performed statistical and bioinformatics analyses. SGC, KML, JHK, HYC, and CY wrote the manuscript. SGC, KML and JHK provided administrative, technical, or materials supports. All authors read and approved the final manuscript.

\section{Ethics approval}

All animal experiments were performed in accordance with protocols reviewed and approved by Institutional Animal Care and Use Committee (IACUC) of Konkuk University.

\section{Consent for publication}

Not applicable.

\section{Competing interests}

The authors declare that they have no competing interests.

\section{Publisher's Note}

Springer Nature remains neutral with regard to jurisdictional claims in published maps and institutional affiliations.

\section{Author details}

'Department of Stem Cell \& Regenerative Biotechnology and Incurable Disease Animal Model and Stem Cell Institute (IDASI), Konkuk University, 120 Neungdong-ro, Gwangjin-gu, Seoul 05029, Republic of Korea. ${ }^{2}$ Department of Biochemistry and Molecular Biology, Korea University College of Medicine, 26-1 Anam-dong, Sungbuk-gu, Seoul 02841, Republic of Korea. ${ }^{3}$ Department of Surgery, Konkuk University School of Medicine, Seoul 05030, Republic of Korea. ${ }^{4}$ Department of Melanoma Medical Oncology, MD Anderson Cancer Center, Houston, TX 77054, USA.

\section{Received: 21 June 2018 Accepted: 26 October 2018}

Published online: 16 January 2019

\section{References}

1. Kreso A, Dick JE. Evolution of the cancer stem cell model. Cell Stem Cell. 2014;14(3):275-91.

2. Alix-Panabieres $C$, Pantel K. Challenges in circulating tumour cell research. Nat Rev Cancer. 2014;14(9):623-31.

3. Aceto N, Bardia A, Miyamoto DT, Donaldson MC, Wittner BS, Spencer JA, Yu M, Pely A, Engstrom A, Zhu H, et al. Circulating tumor cell clusters are oligoclonal precursors of breast cancer metastasis. Cell. 2014;158(5):1110-22.

4. Yu M, Bardia A, Wittner BS, Stott SL, Smas ME, Ting DT, Isakoff SJ, Ciciliano JC, Wells MN, Shah AM, et al. Circulating breast tumor cells exhibit dynamic changes in epithelial and mesenchymal composition. Science. 2013; 339(6119):580-4.

5. Fidler IJ. The pathogenesis of cancer metastasis: the 'seed and soil' hypothesis revisited. Nat Rev Cancer. 2003;3(6):453-8.

6. van Staalduinen J, Baker D, Ten Dijke P, van Dam H. Epithelialmesenchymal-transition-inducing transcription factors: new targets for tackling chemoresistance in cancer? Oncogene. 2018;37(48):6195-6211.

7. Lambert AW, Pattabiraman DR, Weinberg RA. Emerging biological principles of metastasis. Cell. 2017;168(4):670-91.

8. Labernadie A, Kato T, Brugues A, Serra-Picamal X, Derzsi S, Arwert E, Weston A, Gonzalez-Tarrago V, Elosegui-Artola A, Albertazzi L, et al. A mechanically active heterotypic E-cadherin/N-cadherin adhesion enables fibroblasts to drive cancer cell invasion. Nat Cell Biol. 2017;19(3):224-37.

9. Kessenbrock K, Plaks V, Werb Z. Matrix metalloproteinases: regulators of the tumor microenvironment. Cell. 2010;141(1):52-67.

10. Gkretsi V, Stylianou A, Papageorgis P, Polydorou C, Stylianopoulos T. Remodeling components of the tumor microenvironment to enhance cancer therapy. Front Oncol. 2015;5:214.

11. Reneman RS, Hoeks AP. Wall shear stress as measured in vivo: consequences for the design of the arterial system. Med Biol Eng Comput. 2008;46(5):499-507.

12. Malek AM, Alper SL, Izumo S. Hemodynamic shear stress and its role in atherosclerosis. JAMA. 1999;282(21):2035-42.
13. Barnes JM, Nauseef JT, Henry MD. Resistance to fluid shear stress is a conserved biophysical property of malignant cells. PLoS One. 2012;7(12): e50973.

14. Mitchell MJ, King MR. Computational and experimental models of cancer cell response to fluid shear stress. Front Oncol. 2013;3:44.

15. Ding $Z$, Liu S, Wang $X$, Deng $X$, Fan $Y$, Sun C, Wang $Y$, Mehta JL. Hemodynamic shear stress via ROS modulates PCSK9 expression in human vascular endothelial and smooth muscle cells and along the mouse aorta. Antioxid Redox Signal. 2015;22(9):760-71.

16. Flitney EW, Kuczmarski ER, Adam SA, Goldman RD. Insights into the mechanical properties of epithelial cells: the effects of shear stress on the assembly and remodeling of keratin intermediate filaments. FASEB J. 2009;23(7):2110-9.

17. Liu J, Bi X, Chen T, Zhang Q, Wang SX, Chiu JJ, Liu GS, Zhang Y, Bu P, Jiang F. Shear stress regulates endothelial cell autophagy via redox regulation and Sirt1 expression. Cell Death Dis. 2015;6:e1827.

18. Adamo L, Naveiras O, Wenzel PL, McKinney-Freeman S, Mack PJ, GraciaSancho J, Suchy-Dicey A, Yoshimoto M, Lensch MW, Yoder MC, et al. Biomechanical forces promote embryonic haematopoiesis. Nature. 2009; 459(7250):1131-5.

19. Wirtz D, Konstantopoulos K, Searson PC. The physics of cancer: the role of physical interactions and mechanical forces in metastasis. Nat Rev Cancer. 2011;11(7):512-22.

20. Ma S, Fu A, Lim S, Chiew GGY, Luo KQ. MnSOD mediates shear stresspromoted tumor cell migration and adhesion. Free Radic Biol Med. 2018; 129:46-58.

21. Strilic B, Offermanns S. Intravascular survival and extravasation of tumor cells. Cancer Cell. 2017;32(3):282-93.

22. Kwan TT, Bardia A, Spring LM, Giobbie-Hurder A, Kalinich M, Dubash T, Sundaresan T, Hong X, LiCausi JA, Ho U, et al. A digital RNA signature of circulating Tumor cells predicting early therapeutic response in localized and metastatic breast cancer. Cancer Discov. 2018;8(10):1286-1299.

23. Dardik A, Chen L, Frattini J, Asada H, Aziz F, Kudo FA, Sumpio BE. Differential effects of orbital and laminar shear stress on endothelial cells. J Vasc Surg. 2005;41(5):869-80.

24. Chiu JJ, Chien S. Effects of disturbed flow on vascular endothelium: pathophysiological basis and clinical perspectives. Physiol Rev. 2011;91(1): 327-87.

25. Tsubota Y, Frey JM, Raines EW. Novel ex vivo culture method for human monocytes uses shear flow to prevent total loss of transendothelial diapedesis function. J Leukoc Biol. 2014;95(1):191-5.

26. Lim KT, Hexiu J, Kim J, Seonwoo H, Choung PH, Chung JH. Synergistic effects of orbital shear stress on in vitro growth and osteogenic differentiation of human alveolar bone-derived mesenchymal stem cells. Biomed Res Int. 2014;2014:316803.

27. Mahmoud MM, Serbanovic-Canic J, Feng S, Souilhol C, Xing R, Hsiao S, Mammoto A, Chen J, Ariaans M, Francis SE, et al. Shear stress induces endothelial-to-mesenchymal transition via the transcription factor Snail. Sci Rep. 2017;7(1):3375.

28. Shaw FL, Harrison H, Spence K, Ablett MP, Simoes BM, Farnie G, Clarke RB. A detailed mammosphere assay protocol for the quantification of breast stem cell activity. J Mammary Gland Biol Neoplasia. 2012;17(2):111-7.

29. Salmon P, Trono D. Production and titration of lentiviral vectors. Curr Protoc Hum Genet. 2007; Chapter 12(Unit 12.10).

30. Charles N, Hardwick D, Daugas E, Illei GG, Rivera J. Basophils and the T helper 2 environment can promote the development of lupus nephritis. Nat Med. 2010;16(6):701-7.

31. Han D, Kim HJ, Choi HY, Kim B, Yang G, Han J, Dayem AA, Lee HR, Kim JH, Lee KM, et al. 3,2'-Dihydroxyflavone-treated pluripotent stem cells show enhanced proliferation, pluripotency marker expression, and neuroprotective properties. Cell Transplant. 2015;24(8):1511-32.

32. Chiu JJ, Chen LJ, Lee PL, Lee Cl, Lo LW, Usami S, Chien S. Shear stress inhibits adhesion molecule expression in vascular endothelial cells induced by coculture with smooth muscle cells. Blood. 2003;101(7):2667-74.

33. Lan $Q$, Mercurius KO, Davies PF. Stimulation of transcription factors NF kappa B and AP1 in endothelial cells subjected to shear stress. Biochem Biophys Res Commun. 1994;201(2):950-6.

34. Triantafillu UL, Park S, Klaassen NL, Raddatz AD, Kim Y. Fluid shear stress induces cancer stem cell-like phenotype in MCF7 breast cancer cell line without inducing epithelial to mesenchymal transition. Int J Oncol. 2017;50(3):993-1001.

35. Yan Q, Zhang W, Wu Y, Wu M, Zhang M, Shi X, Zhao J, Nan Q, Chen Y, Wang $L$, et al. KLF8 promotes tumorigenesis, invasion and metastasis of 
colorectal cancer cells by transcriptional activation of FHL2. Oncotarget. 2015;6(28):25402-17.

36. Sathanoori R, Rosi F, Gu BJ, Wiley JS, Muller CE, Olde B, Erlinge D. Shear stress modulates endothelial KLF2 through activation of P2X4. Purinergic Signal. 2015;11(1):139-53.

37. Dai G, Kaazempur-Mofrad MR, Natarajan S, Zhang Y, Vaughn S, Blackman BR, Kamm RD, Garcia-Cardena G, Gimbrone MA Jr. Distinct endothelial phenotypes evoked by arterial waveforms derived from atherosclerosissusceptible and -resistant regions of human vasculature. Proc Natl Acad Sci U S A. 2004;101(41):14871-6.

38. Chakraborty A, Chakraborty S, Jala VR, Haribabu B, Sharp MK, Berson RE. Effects of biaxial oscillatory shear stress on endothelial cell proliferation and morphology. Biotechnol Bioeng. 2012;109(3):695-707.

39. Kinney MA, Saeed R, McDevitt TC. Systematic analysis of embryonic stem cell differentiation in hydrodynamic environments with controlled embryoid body size. Integr Biol. 2012;4(6):641-50.

40. Durussel JJ, Berthault MF, Guiffant G, Dufaux J. Effects of red blood cell hyperaggregation on the rat microcirculation blood flow. Acta Physiol Scand. 1998;163(1):25-32

41. Barrett LE, Granot Z, Coker C, lavarone A, Hambardzumyan D, Holland EC, Nam HS, Benezra R. Self-renewal does not predict tumor growth potential in mouse models of high-grade glioma. Cancer Cell. 2012;21(1):11-24.

42. Wei W, Lewis MT. Identifying and targeting tumor-initiating cells in the treatment of breast cancer. Endocr Relat Cancer. 2015;22(3):R135-55.

43. Jain RK. Normalization of tumor vasculature: an emerging concept in antiangiogenic therapy. Science. 2005;307(5706):58-62.

44. Zhao W, Zhao T, Chen Y, Ahokas RA, Sun Y. Reactive oxygen species promote angiogenesis in the infarcted rat heart. Int J Exp Pathol. 2009;90(6):621-9.

45. Woldman YY, Eubank TD, Mock AJ, Stevens NC, Varadharaj S, Turco J, Gavrilin MA, Branchini BR, Khramtsov W. Detection of nitric oxide production in cell cultures by luciferin-luciferase chemiluminescence. Biochem Biophys Res Commun. 2015;465(2):232-8.

46. Nagarajan S, Raj RK, Saravanakumar V, Balaguru UM, Behera J, Rajendran VK, Shathya Y, Ali BM, Sumantran V, Chatterjee S. Mechanical perturbations trigger endothelial nitric oxide synthase activity in human red blood cells. Sci Rep. 2016:6:26935.

47. Aicher A, Heeschen C, Mildner-Rihm C, Urbich C, Ihling C, Technau-lhling K, Zeiher AM, Dimmeler S. Essential role of endothelial nitric oxide synthase for mobilization of stem and progenitor cells. Nat Med. 2003;9(11):1370-6.

48. Ying QL, Wray J, Nichols J, Batlle-Morera L, Doble B, Woodgett J, Cohen P, Smith A. The ground state of embryonic stem cell self-renewal. Nature. 2008;453(7194):519-23.

49. Marks H, Kalkan T, Menafra R, Denissov S, Jones K, Hofemeister H, Nichols J, Kranz A, Stewart AF, Smith A, et al. The transcriptional and epigenomic foundations of ground state pluripotency. Cell. 2012;149(3):590-604.

50. Gao D, Joshi N, Choi H, Ryu S, Hahn M, Catena R, Sadik H, Argani P, Wagner $P$, Vahdat $L T$, et al. Myeloid progenitor cells in the premetastatic lung promote metastases by inducing mesenchymal to epithelial transition Cancer Res. 2012;72(6):1384-94.

51. Fischer KR, Durrans A, Lee S, Sheng J, Li F, Wong ST, Choi H, El Rayes T, Ryu S, Troeger J, et al. Epithelial-to-mesenchymal transition is not required for lung metastasis but contributes to chemoresistance. Nature. 2015;527(7579):472-6.

52. Zheng X, Carstens JL, Kim J, Scheible M, Kaye J, Sugimoto H, Wu CC, LeBleu VS, Kalluri R. Epithelial-to-mesenchymal transition is dispensable for metastasis but induces chemoresistance in pancreatic cancer. Nature. 2015; 527(7579):525-30.

53. Lee HJ, Diaz MF, Price KM, Ozuna JA, Zhang S, Sevick-Muraca EM, Hagan JP, Wenzel PL. Fluid shear stress activates YAP1 to promote cancer cell motility. Nat Commun. 2017:8:14122.

54. Januchowski R, Wojtowicz K, Zabel M. The role of aldehyde dehydrogenase (ALDH) in cancer drug resistance. Biomed Pharmacother. 2013;67(7):669-80.

55. Bertolini G, D'Amico L, Moro M, Landoni E, Perego P, Miceli R, Gatti L, Andriani F, Wong D, Caserini R, et al. Microenvironment-modulated metastatic CD133+/CXCR4+/EpCAM- lung cancer-initiating cells sustain tumor dissemination and correlate with poor prognosis. Cancer Res. 2015; 75(17):3636-49.

56. Sankpal NV, Mayfield JD, Willman MW, Fleming TP, Gillanders WE. Activator protein 1 (AP-1) contributes to EpCAM-dependent breast cancer invasion. Breast Cancer Res. 2011;13(6):R124.

57. Katz M, Amit I, Yarden Y. Regulation of MAPKs by growth factors and receptor tyrosine kinases. Biochim Biophys Acta. 2007;1773(8):1161-76.
58. Samatar AA, Poulikakos PI. Targeting RAS-ERK signalling in cancer: promises and challenges. Nat Rev Drug Discov. 2014;13(12):928-42.

59. Liu Y, Li F, Gao F, Xing L, Qin P, Liang X, Zhang J, Qiao X, Lin L, Zhao Q, et al. Periostin promotes tumor angiogenesis in pancreatic cancer via Erk/ VEGF signaling. Oncotarget. 2016;7(26):40148-59.

60. Gregg J, Fraizer G. Transcriptional regulation of EGR1 by EGF and the ERK signaling pathway in prostate cancer cells. Genes Cancer. 2011;2(9):900-9.

61. Bai YP, Shang $K$, Chen H, Ding F, Wang Z, Liang C, Xu Y, Sun MH, Li YY. FGF1/-3/FGFR4 signaling in cancer-associated fibroblasts promotes tumor progression in colon cancer through Erk and MMP-7. Cancer Sci. 2015; 106(10):1278-87.

62. Arkun Y. Dynamic modeling and analysis of the cross-talk between insulin/ AKT and MAPK/ERK signaling pathways. PLoS One. 2016;11(3):e0149684.

63. Park EK, Lee JC, Park JW, Bang SY, Yi SA, Kim BK, Park JH, Kwon SH, You JS, Nam SW, et al. Transcriptional repression of cancer stem cell marker CD133 by tumor suppressor p53. Cell Death Dis. 2015;6:e1964.

64. Lin T, Chao C, Saito S, Mazur SJ, Murphy ME, Appella E, Xu Y. p53 induces differentiation of mouse embryonic stem cells by suppressing Nanog expression. Nat Cell Biol. 2005;7(2):165-71

Ready to submit your research? Choose BMC and benefit from:

- fast, convenient online submission

- thorough peer review by experienced researchers in your field

- rapid publication on acceptance

- support for research data, including large and complex data types

- gold Open Access which fosters wider collaboration and increased citations

- maximum visibility for your research: over $100 \mathrm{M}$ website views per year

At BMC, research is always in progress.

Learn more biomedcentral.com/submissions 